\title{
Article \\ Characterization of Type 1 Angiotensin II Receptor Activation Induced Dual-Specificity MAPK Phosphatase Gene Expression Changes in Rat Vascular Smooth Muscle Cells
}

\author{
Janka Borbála Gém ${ }^{1,+}$, Kinga Bernadett Kovács ${ }^{1,+}$, Laura Szalai ${ }^{1,2} \mathbb{D}$, Gyöngyi Szakadáti ${ }^{1}$, Edit Porkoláb ${ }^{1,2}$, \\ Bence Szalai ${ }^{1}$, Gábor Turu ${ }^{1,2} \mathbb{D}$, András Dávid Tóth ${ }^{1,2,3} \mathbb{D}^{\mathbb{D}}$, Mária Szekeres ${ }^{1,4} \mathbb{D}$, László Hunyady ${ }^{1,2, *}$ and \\ András Balla 1,2,*
}

Citation: Gém, J.B.; Kovács, K.B.; Szalai, L.; Szakadáti, G.; Porkoláb, E.; Szalai, B.; Turu, G.; Tóth, A.D.; Szekeres, M.; Hunyady, L.; et al. Characterization of Type 1

Angiotensin II Receptor Activation Induced Dual-Specificity MAPK Phosphatase Gene Expression Changes in Rat Vascular Smooth Muscle Cells. Cells 2021, 10, 3538. https://doi.org/10.3390/cells10123538

Academic Editor: Andrea Hartner

Received: 12 November 2021 Accepted: 10 December 2021 Published: 15 December 2021

Publisher's Note: MDPI stays neutral with regard to jurisdictional claims in published maps and institutional affiliations.

Copyright: (c) 2021 by the authors. Licensee MDPI, Basel, Switzerland. This article is an open access article distributed under the terms and conditions of the Creative Commons Attribution (CC BY) license (https:// creativecommons.org/licenses/by/ $4.0 /)$.
1 Department of Physiology, Faculty of Medicine, Semmelweis University, 1085 Budapest, Hungary; gem.janka@phd.semmelweis.hu (J.B.G.); kovacs.kinga@phd.semmelweis.hu (K.B.K.); laura.szalai42@gmail.com (L.S.); szakadati.gyongyi@gmail.com (G.S.); porkolabeda@gmail.com (E.P.); ben.szalai@gmail.com (B.S.); turu.gabor@med.semmelweis-univ.hu (G.T.); toth.andras1@med.semmelweis-univ.hu (A.D.T.); szekeres.maria@med.semmelweis-univ.hu (M.S.)

2 MTA-SE Laboratory of Molecular Physiology, Hungarian Academy of Sciences and Semmelweis University, 1085 Budapest, Hungary

3 Department of Internal Medicine and Hematology, Semmelweis University, 1085 Budapest, Hungary

4 Department of Morphology and Physiology, Faculty of Health Sciences, Semmelweis University, 1085 Budapest, Hungary

* Correspondence: hunyady.laszlo@med.semmelweis-univ.hu (L.H.); balla.andras@med.semmelweis-univ.hu (A.B.); Tel.: +36-1-459-1500/60401 (L.H.); +36-1-459-1500/60450 (A.B.); Fax: +36-1-266-6504 (L.H.); +36-1-266-6504 (A.B.)

+ These authors contributed equally to this work.

Abstract: Activation of the type I angiotensin receptor (AT1-R) in vascular smooth muscle cells (VSMCs) plays a crucial role in the regulation of blood pressure; however, it is also responsible for the development of pathological conditions such as vascular remodeling, hypertension and atherosclerosis. Stimulation of the VSMC by angiotensin II (AngII) promotes a broad variety of biological effects, including gene expression changes. In this paper, we have taken an integrated approach in which an analysis of AngII-induced gene expression changes has been combined with the use of small-molecule inhibitors and lentiviral-based gene silencing, to characterize the mechanism of signal transduction in response to AngII stimulation in primary rat VSMCs. We carried out Affymetrix GeneChip experiments to analyze the effects of AngII stimulation on gene expression; several genes, including DUSP5, DUSP6, and DUSP10, were identified as upregulated genes in response to stimulation. Since various dual-specificity MAPK phosphatase (DUSP) enzymes are important in the regulation of mitogen-activated protein kinase (MAPK) signaling pathways, these genes have been selected for further analysis. We investigated the kinetics of gene-expression changes and the possible signal transduction processes that lead to altered expression changes after AngII stimulation. Our data shows that the upregulated genes can be stimulated through multiple and synergistic signal transduction pathways. We have also found in our gene-silencing experiments that epidermal growth factor receptor (EGFR) transactivation is not critical in the AngII-induced expression changes of the investigated genes. Our data can help us understand the details of AngIIinduced long-term effects and the pathophysiology of AT1-R. Moreover, it can help to develop potential interventions for those symptoms that are induced by the over-functioning of this receptor, such as vascular remodeling, cardiac hypertrophy or atherosclerosis.

Keywords: angiotensin II (AngII); dual-specificity MAPK phosphatase (DUSP); epidermal growth factor receptor (EGFR); G protein-coupled receptor (GPCR); mitogen-activated protein kinase (MAPK); type 1 angiotensin receptor $\left(\mathrm{AT}_{1}-\mathrm{R}\right)$; vascular smooth muscle cell (VSMC) 


\section{Introduction}

Angiotensin II (AngII) is an octapeptide hormone that is the main effector of the reninangiotensin system, and participates in the physiological and pathological mechanisms leading to cardiovascular diseases. The resulting pathophysiological changes, such as vascular remodeling, atherosclerosis and hypertension, are mainly due to the exaggerated action of AngII, which results in hyperplasia and hypertrophy in the cardiovascular tissues [1]. AngII most importantly acts through the type 1 angiotensin II receptor $\left(\mathrm{AT}_{1}-\mathrm{R}\right)$, a versatile $\mathrm{G}$ protein-coupled receptor (GPCR) that is able to promote a broad variety of biological effects, both short-term and long-term [1,2]. AngII regulates the vascular tone in vascular smooth muscle cells (VSMCs) and it is also an important regulator of cell proliferation and vascular remodeling. The $\mathrm{AT}_{1}-\mathrm{R}$ largely acts via heterotrimeric $\mathrm{G}_{\mathrm{q} / 11}$ activation in VSMCs, resulting in second messenger generation $\left(\mathrm{Ca}^{2+}\right.$ signal via inositol trisphosphate and diacylglycerol) upon agonist binding. This "classical" $\mathrm{G}_{\mathrm{q} / 11}$ protein-mediated signaling mechanism is responsible for the majority of AngII-evoked physiological responses in target cells, but $A_{1}-\mathrm{R}$ is able to activate $G_{i / o}$ or $G_{12 / 13}$ proteins as well $[3,4]$. In addition, there are other $\mathrm{AT}_{1}-\mathrm{R}$-mediated signaling mechanisms that are AngII-induced and independent of $\mathrm{G}$ protein coupling [5].

AngII stimulation also triggers the activation of receptor tyrosine kinases, among which EGFR transactivation plays the most important role in the cardiovascular system [1]. EGFR transactivation is mediated by matrix metalloprotease activation, which causes the shedding of heparin-binding epidermal growth factor-like growth factor (HB-EGF) resulting in agonist release and binding to EGFR [6,7]. The EGFR transactivation has been proven to be an important factor in the long-term effects of AngII in VSMCs, including cell proliferation. It is also responsible for the development of several pathophysiological conditions in the cardiovascular system, such as vascular remodeling and atherosclerosis [1]. In addition to EGFR transactivation, platelet-derived growth factor receptor and insulin-like growth factor I receptor transactivation appears to be important in cardiovascular cells [1].

The vascular smooth muscle is one of the main targets of AngII. Its stimulation activates numerous signaling pathways that cause contraction and could also result in gene expression changes in VSMCs (Supplementary Figure S1). Although much is understood regarding the mechanisms involved in the regulation of AngII-induced gene expression in various cells [8-13], less information is available about the signal transduction pathways involved in primary VSMCs. In this work, we used rat primary isolated VSMCs for our studies to provide more relevant results than we could achieve by studying immortalized cell lines. Although rat primary VSMCs can be maintained up to 20-30 passages, it was demonstrated that primary cultured VSMCs undergo phenotypic modulations [14]. These changes can manifest as early as 7-9 days into primary cell culturing [15]. We carried out the experiments up to 3 passages in order to keep the molecular machinery of the cells as similar to their in vivo conditions as possible.

Mitogen-activated protein kinases (MAPKs), such as ERK1/2, JNK, and p38 MAPK, play an important role in the regulation of various functions in VSMCs and they are general mediators of AngII-evoked cellular responses [16]. The MAPKs require dual phosphorylation of both threonine and tyrosine residues within their activation motif for activation by MAPK kinases. The duration and the magnitude of MAPK activation determine cellular functions such as cell proliferation, gene expression, differentiation, cell death, and metabolism. The activation states of MAPKs are primarily regulated by a family of dualspecificity MAPK phosphatases (DUSPs). DUSPs can dephosphorylate both threonine and tyrosine residues within their activation loop. In addition, they control the duration and the spatiotemporal properties of the MAPK pathways; hence, they are important regulators of MAPK signaling in the cells $[17,18]$. Interestingly, the binding of DUSPs to MAPKs does not require the phosphorylated, active state of the MAPKs; thus, DUSPs can regulate the availability of various MAPKs and they serve as versatile regulators of MAPK signaling. To date, at least 11 DUSPs have been described in the regulation of activity patterns of MAPKs. DUSPs can be divided into three subfamilies, based on domain structure and subcellular 
localization [18,19]. DUSP1, DUSP2, DUSP4 and DUSP5 are localized in the nucleus where they can dephosphorylate all three MAPKs, whereas DUSP6, DUSP7 and DUSP9 largely dephosphorylate ERK1/2 MAPK in the cytoplasm. DUSP8, DUSP10, DUSP14 and DUSP16 can be localized in both the nucleus and the cytoplasm, and they mainly regulate the JNK and p38 MAPKs, except for DUSP8, which is more specific for ERK1/2 [20]. The various DUSPs are transiently induced by cellular stresses, or mitogens such as growth factors, and affect the activity of MAPKs. It is well established that their activity and expression are dependent on the regulated MAPKs, thus providing a feedback loop [18].

In the present study, we have sought to investigate the change in transcriptome and identify novel, potentially important but not yet well-characterized proteins that are involved in the action of AngII using primary VSMCs up to their 3 passages. Our transcriptome analysis revealed the upregulation of several DUSP genes, such as DUSP4, $5,6,10$, and 14. In our further analysis, we have chosen one DUSP gene from each subfamily (based on their intracellular localization), such as DUSP5, DUSP6, and DUSP10, to investigate gene expression changes in response to AngII stimulation.

\section{Materials and Methods}

\subsection{Materials}

Cell culture dishes and plates were purchased from Greiner (Kremsmunster, Austria). Unless otherwise stated, all molecular biology and cell-culture reagents were from Thermo Fisher Scientific (Waltham, MA, USA). Fast Start Essential DNA Green Master Mix was sourced from Roche Applied Science (Basel, Switzerland). The RNeasy Plus Mini Kit was from Qiagen (Hilden, Germany). To maintain cell cultures, Dulbecco's Modified Eagle Medium (DMEM) was purchased from Biosera (Nuaille, France). Heat-inactivated fetal bovine serum, Glutamax and penicillin/streptomycin were supplied by Invitrogen (Carlsbad, CA, USA). Immobilon Western Chemiluminescent HRP substrate was purchased from Merck-Millipore (Billerica, MA, USA), Radiance Plus Femtogram HRP substrate was obtained from Azure Biosystems (Dublin, CA, USA). Glycerol, sodium dodecyl sulfate (SDS) and 40\% acrylamide/bis solution were obtained from Serva (Heidelberg, Germany). Tween 20 and 2-mercapto-ethanol, bromophenol blue, phosphatase inhibitor cocktail 2 were purchased from Sigma-Aldrich (St. Louis, MO, USA). The protease inhibitor cOmplete used in sample preparation for immunoblotting was obtained from Roche Applied Science (Basel, Switzerland). Immunoblot signals were detected with an Azure c600 device (Azure Biosystems, Dublin, CA, USA). The Lenti-X Concentrator kit was from Takara Bio (Kusatsu, Japan). To measure lentivirus concentrations, we used a Lentivirus Titer Kit (Applied Biological Materials, Vancouver, Canada). AngII, EGF, AG1024, AG538, AG1478, BAPTA-AM, CK59, Gefitinib, MMP-2/MMP-9 Inhibitor II, PD98059 and PF 562271 were purchased from Sigma-Aldrich (St. Louis, MO, USA). YM-254890 was obtained from Wako Chemicals (Neuss, Germany). TRV120023 (Sar-Arg-Val-Tyr-Lys-His-Pro-Ala-OH) peptide was synthesized by Proteogenix (Schiltigheim, France) to more than $98 \%$ purity. Gefitinib, Sorafenib and Sunitinib were synthesized by Vichem Chemie Research Ltd. (Budapest, Hungary) as members of NCL (Nested Chemical Library). The purity of the compounds was $>99 \%$, determined by LC-MS and NMR. Anti-pERK1/2, anti-pEGFR, antimouse-HRP and anti-rabbit-HRP were sourced from Cell Signaling Technologies (Danvers, MA, USA). Anti- $\alpha$-actin, anti- $\beta$-actin antibodies and DAPI (4',6-diamidino-2-phenylindole, dihydrochloride) were obtained from Sigma-Aldrich (St. Louis, MO, USA). Alexa Fluor 488 conjugated anti-mouse IgG was obtained from Invitrogen (Carlsbad, CA, USA).

The human embryonic kidney (HEK293T) cells were sourced from ATCC (ATCC CRL3216; American Type Culture Collection, Manassas, VA, USA). Unless otherwise stated, all other chemicals and reagents were purchased from Sigma-Aldrich (St. Louis, MO, USA).

\subsection{Animals}

Male Wistar rats were used for the preparation of primary VSMCs (170-250 g, Charles River Laboratories-Semmelweis University, Budapest, Hungary). They were kept on a 
standard semisynthetic diet. The animals were then sacrificed by decapitation and rapid bleeding. The investigation conformed to the Guide for the Care and Use of Laboratory Animals (NIH, 8th edition, 2011) as well as to national legal and institutional guidelines for animal care. They were approved by the Animal Care Committee of the Semmelweis University, Budapest, and by the Hungarian authorities (No. 001/2139-4/2012). All procedures followed legal and institutional guidelines of animal care.

\subsection{Isolation of VSMCS}

The rat VSMCs were isolated according to the standard explant method [21]. Briefly, to isolate appropriate amounts of cells for our experiments, over a one-week period, two animals were sacrificed by decapitation and rapid bleeding. After removal of the connective tissue and the adherent fat, the thoracic aorta was excised. The aorta was cut into small sections and the VSMCs were allowed to grow out from the explant for 7-14 days. The VSMCs were maintained by passaging with trypsin and were used between passages 2 and 3 (typically, the experiments were performed at passage 3 ). We used $4-5$ million cells weekly for our experiments. The expression of smooth muscle $\alpha$-actin was confirmed by immunochemistry (Supplementary Figure S1A). The isolated VSMCs exhibited a normal response to AngII stimulation, such as calcium signals and ERK activation (Supplementary Figure S1B, other data not shown).

\subsection{Cell Culture}

The experiments were conducted on a rat aortic primary isolated VSMC cell line, whereas the lentiviral particles were made using the HEK293T cell line. The cells were subcultured in DMEM supplemented with 10\% heat-inactivated fetal bovine serum, $1 \%$ Glutamax and $100 \mathrm{IU} / \mathrm{mL}$ penicillin/streptomycin, in $5 \% \mathrm{CO}_{2}$ at $37^{\circ} \mathrm{C}$. For each experiment, VSMCs were transferred onto 6-well plates and were used at approximately $90 \%$ confluency. Before the experiments, VSMCs were made quiescent by incubating them in serum-free DMEM for 16-24 h.

\subsection{Affymetrix GeneChip}

After serum deprivation, VSMCs were stimulated with $100 \mathrm{nM}$ AngII for $2 \mathrm{~h}$ at $37^{\circ} \mathrm{C}$, then the cells were lysed in Trizol reagent. The quality control of the RNA samples was checked using an Agilent BioAnalyzer RNA Nano lab chip before the array experiments. The total RNA isolation and the Affymetrix Rat Gene 1.0 ST GeneChip Array (Affymetrix, Santa Clara, CA, USA) analysis were performed by UD-GenoMed Medical Genomic Technologies Ltd., University of Debrecen, Debrecen, Hungary). Hybridization and an image scan were performed according to the protocol of UD-GenoMed Medical Genomic Technologies Ltd. The microarray experiment was performed in triplicate. Raw CEL files were background-corrected and normalized using the oligo R package [22], and differential expression (Angiotensin II-Vehiculum) analysis was performed using the limma R package [22]. We used PROGENy pathway activity analysis tool to identify AngII induced pathway activity changes $[23,24]$. Calculated PROGENy pathway activity scores were normalized to null distribution (created by 10,000 random permutations of gene names) to create pathway activity z-scores.

\subsection{DNA Constructs}

For the construction of gene-silencing transfer plasmids, $\mathrm{pLKO} .1$ puro vector was used. This was a gift from Dr. Bob Weinberg (Addgene plasmid \#8453; http:/ /n2t.net/addgene: 8453; access date: 9 December 2021; RRID: Addgene_8453) [25]. The AgeI and EcoRI restriction sites of the pLKO.1 puro vector and the following sequences transcribing short-hairpin RNAs, specific to rat EGFR, were used: shRNA\#1: 5'-GCATAGGCATTGGTGAATTTA-3' shRNA\#2: 5'-GGAAATCACCTATGTGCAAAG-3' or scrambled sequence (control). The oligos were obtained from Sigma-Aldrich. 


\subsection{RNA Extraction and Real-Time PCR}

Cells were washed twice with sterile PBS (137 mM NaCl; $2.7 \mathrm{mM} \mathrm{KCl} 2.7 ; 10.1 \mathrm{mM}$ $\mathrm{Na}_{2} \mathrm{HPO}_{4} ; 1.8 \mathrm{mM} \mathrm{KH}_{2} \mathrm{PO}_{4}, \mathrm{pH}$ 7.4), and the total RNA was isolated with an RNeasy Plus Mini kit from Qiagen. RNA concentrations were determined spectrophotometrically via absorbance at $260 \mathrm{~nm}$ and purity was assessed by the 260/280 and 230/260 $\mathrm{nm}$ ratios. Reverse transcription from total RNA was carried out using a RevertAid Reverse Transcription Kit according to the manufacturer's instructions. Gene expression levels were quantified by quantitative real-time PCR (qRT-PCR). The measurements were performed using the SYBR Green method (SYBR Green I Master, Roche, Basel, Switzerland) using a LightCycler 480. The primers were synthesized by Sigma-Aldrich and designed so that the amplicon sizes were between 100 and 200 base pairs. Efficiency for each primer pair was determined by using serial dilutions of the PCR product.

The thermal cycling program started with pre-incubation at $95{ }^{\circ} \mathrm{C}$ for $5 \mathrm{~min}$, followed by amplification via 45 cycles of $10 \mathrm{~s}$ at $95^{\circ} \mathrm{C}, 5 \mathrm{~s}$ at $62^{\circ} \mathrm{C}$ and $15 \mathrm{~s}$ at $72{ }^{\circ} \mathrm{C}$, melting curve $5 \mathrm{~s}$ at $95^{\circ} \mathrm{C}, 1 \mathrm{~min}$ at $65^{\circ} \mathrm{C}$ and $97^{\circ} \mathrm{C}$, and cooling for $30 \mathrm{~s}$ at $40^{\circ} \mathrm{C}$. Fluorescence data including melting curves were obtained. The cycle threshold $(\mathrm{Ct})$ was calculated via the second derivative method using LightCycler 480 Software. $\Delta \mathrm{Ct}$ represents the difference in $\mathrm{Ct}$ values obtained between the reference and the tested samples. For normalization, the glyceraldehyde-3-phosphate dehydrogenase (GAPDH) housekeeping gene was used. Gene expression levels were plotted against the GAPDH expression level. Fold ratios of gene expression were calculated as follows: ratio $=\mathrm{E}^{\Delta \mathrm{Ct} \text { target gene }} / \mathrm{E}^{\Delta \mathrm{Ct} \mathrm{GAPDH}}$. The following primers were used for qRT-PCR determinations $\left(5^{\prime}-3^{\prime}\right)$ : GAPDH: Forward CCT GCA CCA CCA ACT GCT TAG, Reverse CAG TCT TCT GAG TGG CAG TGA TG; DUSP5: Forward GGC AAG GTC CTG GTT CAC TGT, Reverse GTT GGG AGA GAC CAC GCT CCT; DUSP6: Forward ATC ACT GGA GCC AAA ACC TG, Reverse CGT TCA TGG ACA AGT TGA GC; DUSP10 Forward GGC AAA GAA CCC CTG GTA TT, Reverse AGA AAC AGG AAG GGC AGG AT; EGFR Forward CAT CCA GTG CCA TCC AGA AT, Reverse CTT CCA GAC CAG GGT GTT GT.

\subsection{Treatment Protocols}

Before the experiments, VSMCs were made quiescent by incubating in serum-free DMEM for 16-24 h. For the time-dependency determinations, the serum-starved cells were stimulated with $100 \mathrm{nM}$ AngII for 1-6 h. During the examination of inhibitor effects, the cells were pretreated with the appropriate inhibitor for $30 \mathrm{~min}$, then stimulated for $2 \mathrm{~h}$ with $100 \mathrm{nM}$ AngII or $50 \mathrm{ng} / \mathrm{mL}$ EGF. BAPTA-AM and RO31-8425 pretreatments were used for $10 \mathrm{~min}$ before the 2-h agonist stimulation of the cells.

\subsection{Lentivirus Production}

Lentiviruses were produced by co-transfecting HEK293T cells on 10-cm dishes with pLKO.1puro transfer, the pCMV-VSV-G envelope and pCMV-dR8.2 packaging plasmids (gift from Dr. Bob Weinberg, [25], purchased from Addgene) using the calcium phosphate precipitation method. In summary, plasmid DNAs were mixed in sterile distilled water, then $2.5 \mathrm{M} \mathrm{CaCl}_{2}$ was added (final concentration: $125 \mathrm{mM}$ ) and the solution was mixed dropwise with $2 \times$ HEPES-buffered solution [HBS] (42 mM HEPES, $15 \mathrm{mM}$ D-glucose, $1.4 \mathrm{mM} \mathrm{Na}_{2} \mathrm{HPO}_{4}, 10 \mathrm{mM} \mathrm{KCl}, 274 \mathrm{mM} \mathrm{NaCl} 274 \mathrm{mM}, \mathrm{pH}$ 7.1). This mixture was added dropwise to attached cells and the medium was replaced with fresh complete DMEM after $6 \mathrm{~h}$. After $48 \mathrm{~h}$ had passed post-transfection, the cell medium was collected and centrifuged for $10 \mathrm{~min}$ at $3000 \mathrm{rpm}$, the supernatant was filtered and the lentiviral vector particles were purified and concentrated with a Lenti- $X$ concentrator kit (Takara). After concentration, the viral particles were resuspended in sterile phosphate-buffered saline and the titer of the samples was measured with a qPCR Lentivirus titer kit from Applied Biological Materials (Vancouver, Canada). The samples were stored at $-80{ }^{\circ} \mathrm{C}$ until the infection of cells. 


\subsection{Lentiviral Infection of VSMCS}

Briefly, $2 \times 10^{5}-2.5 \times 10^{5}$ primary vascular smooth muscle cells/well were plated on-6-well plates, and the cells were infected the next day. The same titers of lentiviral preparations, diluted in complete DMEM $+8 \mu \mathrm{g} / \mathrm{mL}$ Polybrene (Sigma-Aldrich), were used to infect the VSMCs. The cells were subjected to the experiments $48 \mathrm{~h}$ after infection.

\subsection{Immunoblot Analysis}

After the agonist stimulation of the VSMCs, cells were scraped with $2 \times$ concentrated Laemmli buffer (Tris-Cl pH 6.8, glycerol, SDS, 2-mercapto-ethanol, bromophenol blue), supplemented with protease and phosphatase inhibitors. This cell lysate was briefly sonicated, then boiled, and equal amounts of samples were loaded into $12 \%$ SDS-polyacrylamide gels. The proteins were transferred to PVDF membranes using $80 \mathrm{~V}$ for $2 \mathrm{~h}$ during the process. The PVDF membranes were then blocked with a 5\% blocking solution (nonfat dried milk diluted in PBS-T). The membranes were then incubated with either pEGFR or pERK1/2 primary antibodies, depending on the experiment. Following PBS-T washing, these membranes were incubated with the appropriate anti-rabbit IgG secondary antibody. As a loading control, $\beta$-actin labeling was used. The signals were visualized with enhanced chemiluminescence, using Immobilon Western HRP substrate reagents, and were then detected with an Azure c600 device.

\subsection{Immunofluorescence Staining}

The immunostaining was performed according to the following protocol: the VSMCs were gently washed, once, before fixation with $3.7 \%$ paraformaldehyde solution for $15 \mathrm{~min}$. After quenching the fixation solution in three washing steps, the cells were permeabilized using $0.1 \%$ Triton X-100 (Sigma-Aldrich) and incubated in 0.1\% sodium-borohydride solution for $15 \mathrm{~min}$. The cells were then incubated in 1\% BSA (Sigma-Aldrich) containing blocking solution for $30 \mathrm{~min}$, then immunolabelled using anti- $\alpha$-smooth muscle actin (Sigma-Aldrich) and Alexa Fluor 488 conjugated secondary antibodies (Invitrogen). Cell nuclei were stained by DAPI (4',6-diamidino-2-phenylindole, dihydrochloride; SigmaAldrich). Photomicrographs were taken using a Leica DMI6000B inverted microscope.

\subsection{Statistical Analysis}

We analyzed gene expression data, collected from qRT-PCR measurements, using multiple linear regression with a $95 \%$ confidence interval in order to determine the significance of inhibitor treatments, stimuli and their interaction on the dependent variable, which is the fold-change value of a given gene of interest. In the case of Figures 2, 4D-F and 6A, ordinary one-way ANOVA analyses were performed to compare stimulated or lentiviral infected groups to control groups. Statistical analysis and graph plotting were carried out with GraphPad Prism 9.1.2 software. The sample size $(n)$ in the figure legends refers to the number of independent experiments (biological replicates). Unless otherwise stated, data are presented as mean $\pm \mathrm{SE}$.

\section{Results}

\subsection{Affymetrix GeneChip Analysis of the AngII Upregulated Genes in VSMCs}

In the present study, we used the Affymetrix GeneChip Rat Gene 1.0 ST array to compare the gene expression profiles of the vehicle and $100 \mathrm{nM}$ AngII-treated VSMCs after $2 \mathrm{~h}$ of treatment. We used rat primary isolated VSMCs in their second passage, in order to get physiologically relevant data. In order to demonstrate that these relatively early-passage young cells possess the expected properties of VSMCs, we performed smooth muscle $\alpha$-actin immunostaining and agonist stimulation of these early passage cells. Our data confirmed that these cells showed characteristic features of VSMCs, such as the expression of smooth muscle $\alpha$-actin and showed a typical ERK1/2 activation pattern in response to $50 \mathrm{ng} / \mathrm{mL}$ EGF or $100 \mathrm{nM}$ AngII stimulation (Supplementary Figure S1). 
We performed differential expression (DE) analysis between the AngII- and vehicletreated microarray samples using limma [21]. AngII led to the significant upregulation (false discovery rate, based on the Benjamini-Hochberg correction $<0.05, \log _{2}$ fold change $>1$ ) of 74 genes (Figure 1A). We found 4 DUSP isoforms among the significantly upregulated genes, namely, DUSP4, DUSP5, DUSP6 and DUSP10 (log2 fold change values: 1.01, 2.66, 2.01 and 1.23, FDR (false discovery rate): $2.5 \times 10^{-04}, 3 \times 10^{-06}, 5 \times 10^{-06}$ and $5.2 \times 10^{-05}$, respectively). We performed a pathway activity analysis using the PROGENy tool to ensure a more unbiased analysis of AngII-induced gene expression changes [22,23]. PROGENy identifies upstream pathways regulating the observed gene expression changes for 14 pathways (Figure 1B). PROGENy analysis revealed that AngII treatment significantly increased the MAPK and EGFR pathways (Figure 1B, z-scores of pathway activities: 21.22 and 22.86, respectively (see the Materials and Methods section for further details)), and also led to a modest increase in another receptor tyrosine kinase pathway (VEGFR) and TGF $\beta$.

A

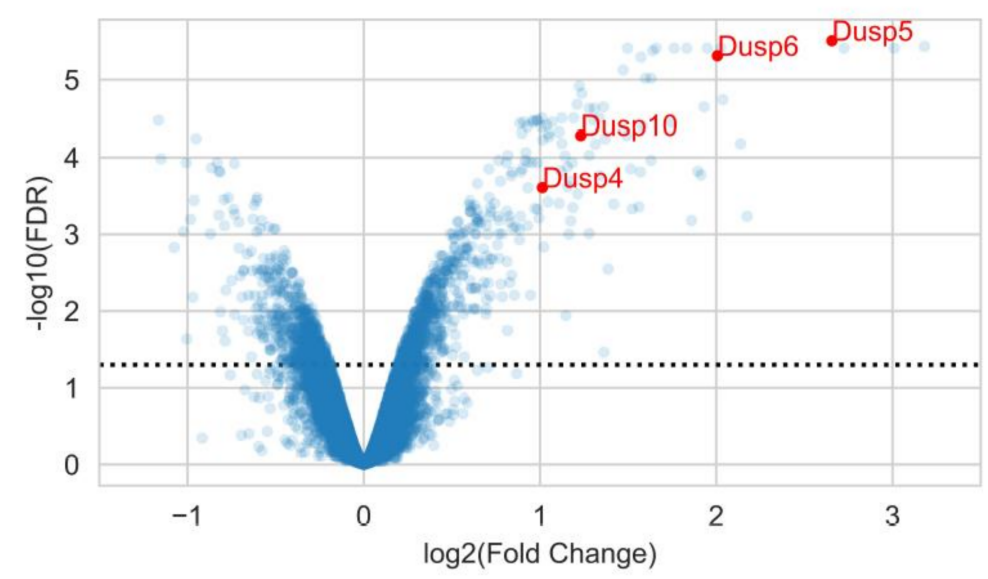

B

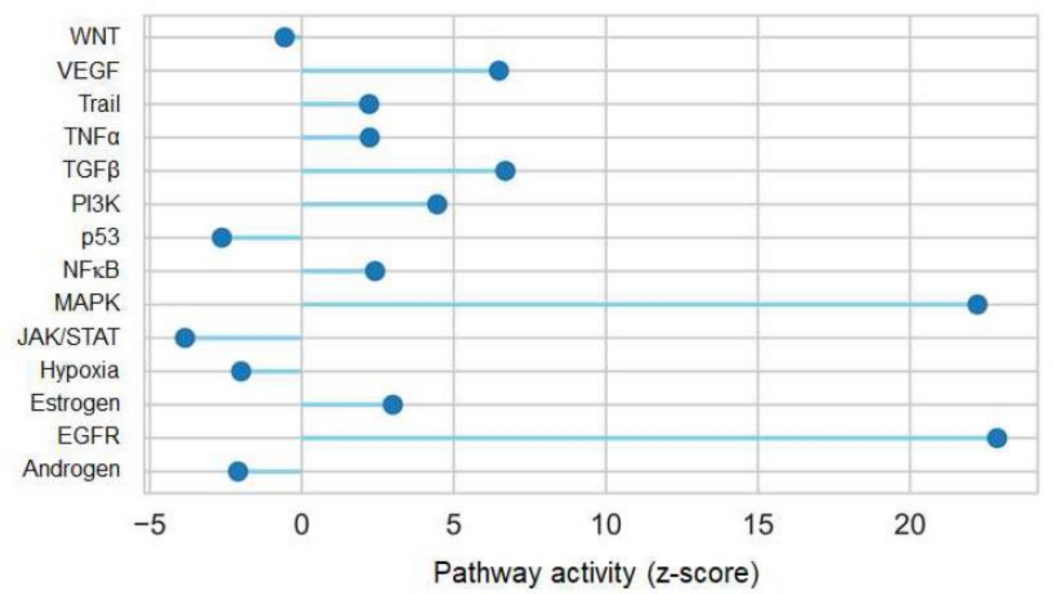

Figure 1. AngII-induced gene expression changes in VSMCs. (A) Differential expression (DE) analysis was performed between 2-hour AngII- and vehicle-treated samples. The microarray experiment was performed in triplicate. The results of DE analysis are shown as a volcano plot $(x$-axis: $\log 2$ fold change, $y$-axis: $-\log 10$ (FDR, false discovery rate), based on the Benjamini-Hochberg correction of p-values. Selected members of the DUSP family are color-coded and text-labeled. The dotted line shows the significance threshold (FDR < 0.05) (B) PROGENy pathway analysis of an AngII-induced gene expression signature. Pathway activity was calculated for 14 PROGENy pathways ( $x$-axis) and normalized to $z$-scores ( $y$-axis), based on a random permutation of gene labels. 
In summary, our microarray analysis revealed that AngII increased the activity of MAPK and EGFR pathways in VSMCs. We found several DUSP isoforms, important negative regulators of the MAPK pathway, among the most significantly overexpressed genes, corresponding to a plausible negative feedback mechanism [26].

3.2. qRT-PCR Measurements Validate the Affymetrix Array Results Regarding the Upregulation of DUSP5, DUSP6, and DUSP10 Gene Expressions, in Response to AngII Stimulation. Time Kinetics of Gene Expression Changes, in Response to the AngII Stimulation of VSMCs

We used qRT-PCR determinations to confirm the effect of AngII stimulation on the expression levels of certain DUSP isoforms. The transcriptome analysis revealed the upregulation of several DUSP genes, such as DUSP 5, 6, 10, 4, and 14. We selected one DUSP from each subfamily of DUSPs, namely, DUSP5, DUSP6, and DUSP10 for our studies. We aimed to validate the Affymetrix GeneChip results, and we also wanted to determine the time course of the AngII-induced DUSP5 (Figure 2A), DUSP6 (Figure 2B) and DUSP10 (Figure 2C) expression-level upregulation. VSMCs were stimulated at different points of time from 1 to $6 \mathrm{~h}$ with $100 \mathrm{nM}$ of AngII, then the mRNA levels were measured via real-time PCR. In the case of DUSP5 and DUSP10, we observed the highest mRNA levels $2 \mathrm{~h}$ after the stimulation. The mRNA levels of DUSP6 were strongly elevated after the first hour, peaked at $2 \mathrm{~h}$, and remained continuously elevated, although they showed a slightly reduced tendency at later time points. Based on the qRT-PCR results, we chose 2-hour-long stimulations for our further experiments concerning the analysis of gene expression changes.

A

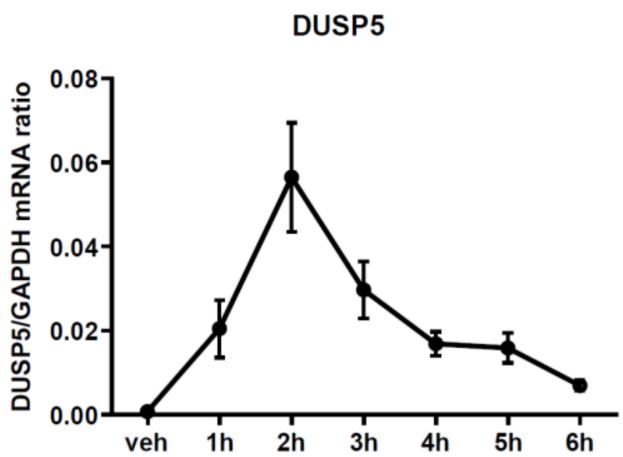

B

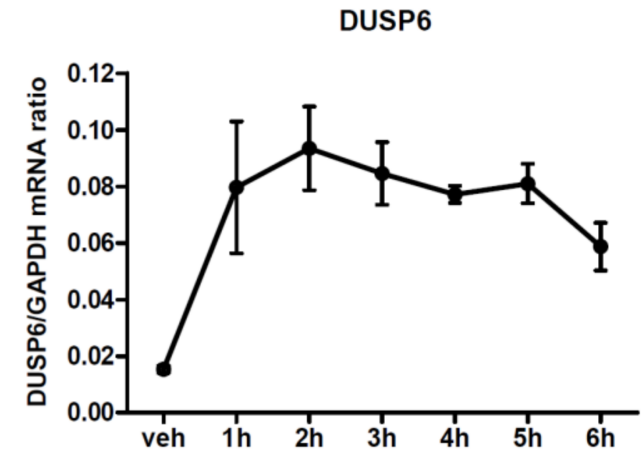

C

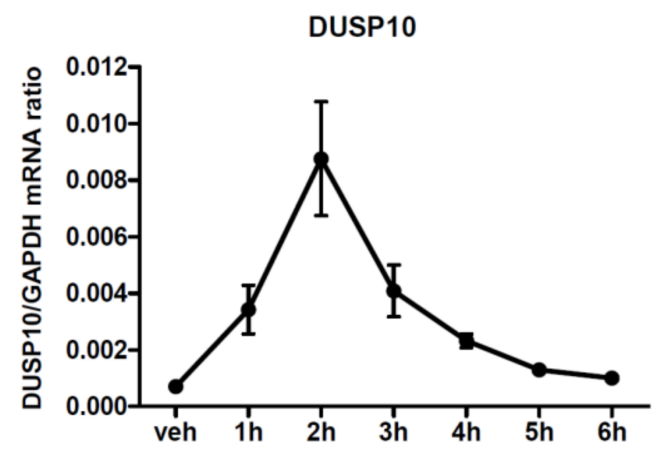

Figure 2. Time-dependent effect of AngII stimulation on gene expression in VSMCs. VSMCs were serum-depleted for $24 \mathrm{~h}$, then cells were treated for various lengths of time intervals with $100 \mathrm{nM}$ AngII, beside a control group treated with the vehicle. Time kinetics of (A) DUSP5, (B) DUSP6, and (C) DUSP10 expression levels are shown. The mRNA abundance was calculated via normalization to the GAPDH housekeeping gene and measured using real-time PCR. Mean values \pm SE are shown $(n=5-6)$. 


\subsection{Investigation of Signaling Pathways Involved in AngII-Mediated Responses}

Next, we wanted to determine which receptor type and coupling $G$ protein is responsible for the expression changes. Theoretically, AngII can stimulate and mediate its effect via two distinct GPCRs, the $\mathrm{AT}_{1}$ and $\mathrm{AT}_{2}$ angiotensin receptors in VSMCs [27]. The $\mathrm{AT}_{1}-\mathrm{R}$ is much more important and is abundantly expressed in vessels. In order to exclude the potential role of the $\mathrm{AT}_{2}$ angiotensin receptor in the investigated gene expression changes, we applied candesartan, a selective $\mathrm{AT}_{1}-\mathrm{R}$ antagonist with insurmountable binding properties. As shown in Figure 3, the candesartan $(10 \mu \mathrm{M})$ pretreatment completely blocked the AngII-mediated upregulation of DUSP levels. This data indicated that $\mathrm{AT}_{1}-\mathrm{R}$ mediates the observed AngII-induced gene expression changes that mostly couple to the $G_{q / 11}$ heterotrimeric $\mathrm{G}$ protein in VSMCs [1].

A

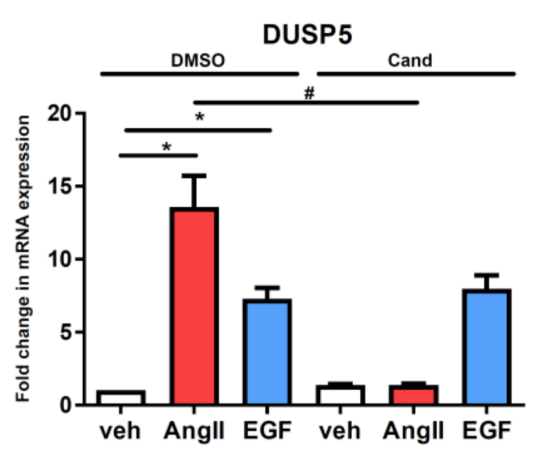

B

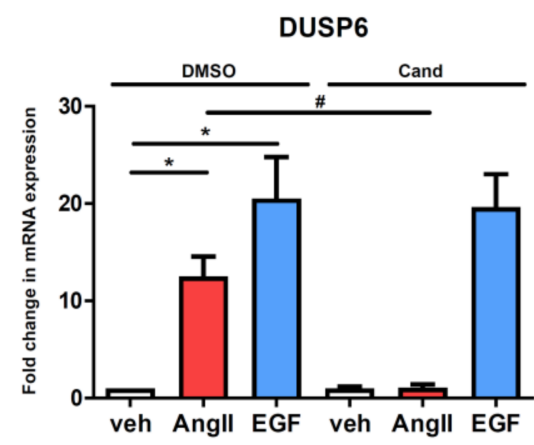

C

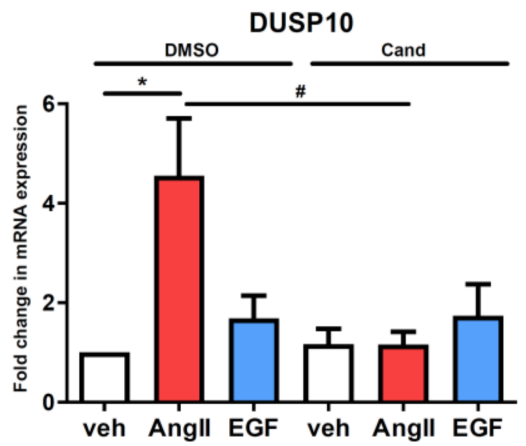

Figure 3. Effect of $\mathrm{AT}_{1}-\mathrm{R}$ antagonist treatment on the agonist-induced gene expression changes of the DUSP isoform in vascular smooth muscle cells. Serum-starved cells were incubated with $10 \mu \mathrm{M}$ candesartan (Cand) or DMSO as a control for $30 \mathrm{~min}$, then the cells were exposed to either $100 \mathrm{nM}$ AngII (red columns) or $50 \mathrm{ng} / \mathrm{mL}$ EGF (blue columns) or the vehicle (white columns) for $2 \mathrm{~h}$. Standardization was made against the GAPDH housekeeping gene. The mRNA levels of DUSP5 (A), DUSP6 (B) and DUSP10 (C) were normalized to values of DMSO vehicle samples and expressed as fold change. Mean values \pm SE are shown. Significance was determined with multiple linear regression. $p<0.05$ was considered as statistically significant. *: statistically significant from vehicle stimulation. \#: statistically significant from DMSO-pretreated agonist-induced response. The values are from four independent experiments $(n=4)$.

It has previously been reported that only the $G$ protein-dependent mechanism of $\mathrm{AT}_{1}$-R seems to be important in AngII-induced hypertrophy in VSMCs [28]. In addition to the $\mathrm{G}_{\mathrm{q} / 11}$ activation mechanism, it is well documented that $\mathrm{AT}_{1}-\mathrm{R}$ can also couple to the $\mathrm{G}_{\mathrm{i} / \mathrm{o}}$ and $\mathrm{G}_{12 / 13}$ heterotrimeric proteins, leading to the inhibition of adenylyl cyclase, the activation of Rho-kinase and phospholipase $\mathrm{D}$, and the regulation of $\mathrm{Ca}^{2+}$ channels [29]. We used YM-254890, a selective $\mathrm{G}_{\mathrm{q} / 11}$ inhibitor, to investigate the role of $\mathrm{G}_{\mathrm{q} / 11}$-mediated pathways. Figure 4 demonstrates that $1 \mu \mathrm{M}$ of YM-254890 completely wiped out the 
AngII-mediated gene expression upregulation in all the examined DUSPs. We also used pertussis toxin (PTX) pretreatment $(100 \mathrm{ng} / \mathrm{mL}$ for $18 \mathrm{~h})$ to inhibit $\mathrm{G}_{\mathrm{i}}$ protein activation and to assess the potential role of the $G_{i}$ protein in the induced gene expression changes. Our results show that the PTX evoked only partial inhibition of the AngII-induced gene expression changes, emphasizing the primary role of $\mathrm{G}_{\mathrm{q} / 11}$ activation (data not shown). We also wanted to evaluate the possible role of $\beta$-arrestin-mediated signaling in the regulation of AngII-induced expression changes. TRV120023 peptide is a biased agonist of $\mathrm{AT}_{1}-\mathrm{R}$ that triggers no or partial activation of $G$ proteins but it induces $\beta$-arrestin-mediated signaling via $\beta$-arrestin binding [30-32]. In contrast to $100 \mathrm{nM}$ AngII stimulation, using $3 \mu \mathrm{M}$ TRV120023 as an $\mathrm{AT}_{1}-\mathrm{R}$ agonist did not evoke significant gene expression changes, which reflects the finding that DUSP upregulation is initiated exclusively in a G-proteindependent manner (Figure 4).

A

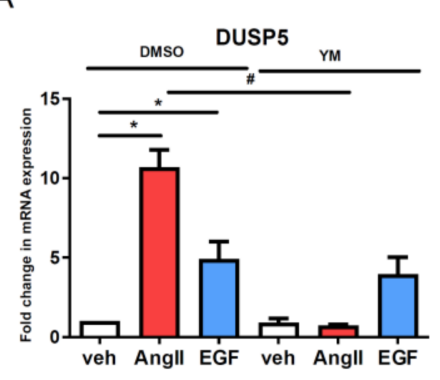

D

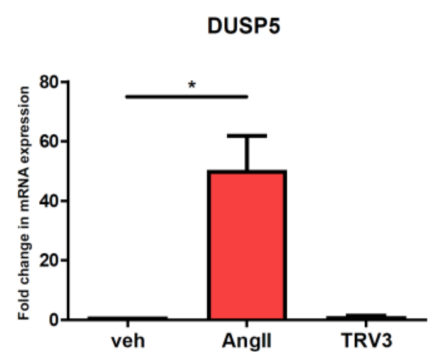

B

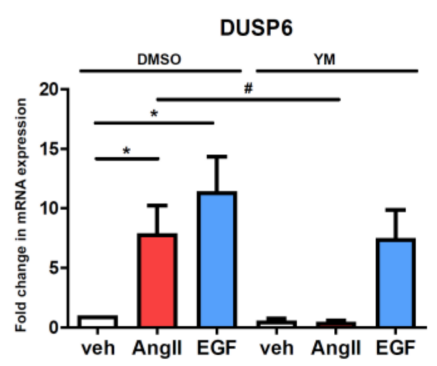

$E$

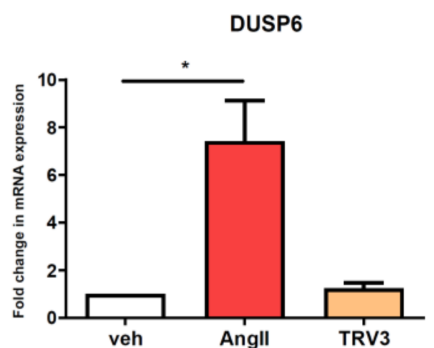

C

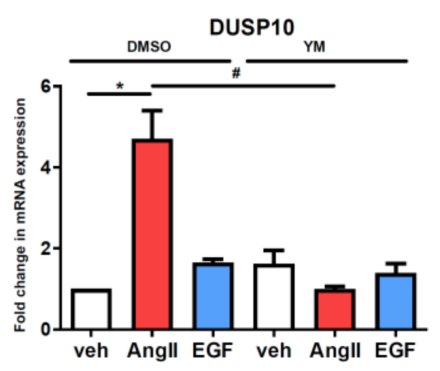

$\mathrm{F}$

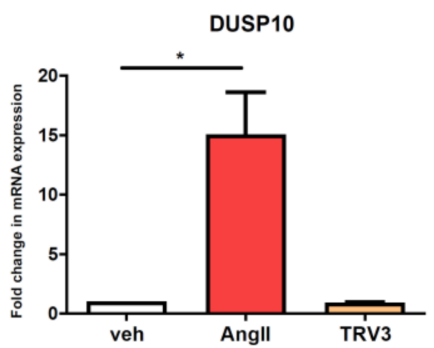

Figure 4. Evaluation of the contribution of G-protein-dependent and independent mechanisms in the $\mathrm{AT}_{1}$-receptor stimulation on induced changes in DUSP levels in vascular smooth muscle cells. Serum-depleted VSMCs were incubated with $1 \mu \mathrm{M}$ YM-254890 (YM) or DMSO as a control for $30 \mathrm{~min}$, then the cells were exposed to either $100 \mathrm{nM}$ AngII (red columns) or $50 \mathrm{ng} / \mathrm{mL}$ EGF (blue columns) or vehicle (white columns) for $2 \mathrm{~h}$ (A-C). The serum-starved VSMCs were exposed to either the vehicle (white columns) or $100 \mathrm{nM}$ AngII I (red columns) or $3 \mu \mathrm{M}$ TRV120023 (beige columns) for $2 \mathrm{~h}$ (D-F). RNA was isolated from VSMCs, then converted to cDNA. cDNA levels of DUSP5 (A,D), DUSP6 (B,E) and DUSP10 (C,F) were measured by qRT-PCR. Standardization was established against the GAPDH housekeeping gene. Mean values \pm SE are shown. Significance was determined via multiple linear regressions. $p<0.05$ was considered as statistically significant. *: statistically significant from vehicle stimulation. \#: statistically significant from DMSO pretreated agonist-induced response (A-C). In the case of $\mathbf{D}-\mathbf{F}$, significance was determined with a one-way ANOVA-test $\left({ }^{*} p<0.05\right)$. The values are from four or five independent experiments $(n=4-5)$.

\subsection{Effect of EGF Stimulation and EGFR Tyrosine Kinase Inhibitors on Agonist-Induced Expression of DUSP Genes}

Since EGF-receptor transactivation plays an important role in the AngII-induced cell responses in VSMCs, we investigated the effect of direct EGF-receptor stimulation on DUSP gene-expression changes. Figure 5 demonstrates that $50 \mathrm{ng} / \mathrm{mL}$ of EGF stimulation caused a significant increase in DUSP5 and DUSP10 expression levels but this was to a lesser extent than the $100 \mathrm{nM}$ AngII stimulus-evoked response (Figure 5A,C). In the case of DUSP6 mRNA levels, we observed a similar increase in both EGF- and AngII-stimulated groups 
(Figure 5B). In order to determine the role and contribution of EGFR transactivation in the AngII-induced changes, we pretreated the VSMCs with either $1 \mu \mathrm{M}$ AG1478 or $2.5 \mu \mathrm{M}$ gefitinib, two widely used EGFR tyrosine kinase inhibitors. As expected, these inhibitors completely blocked the EGF-induced increase of DUSP5, DUSP6, and DUSP10 mRNA levels (Figure 5). It is noteworthy that neither candesartan nor YM-254890 evoked a significant effect on the EGF-induced increase in DUSP expression levels, showing the specificity of the candesartan and YM-254890 on AngII-induced responses (Figures 3 and 4A-C). It is important to note that although the AngII-induced upregulation of DUSP levels was significantly blunted by AG1478 and gefitinib pretreatment, these inhibitory effects were not total.

A

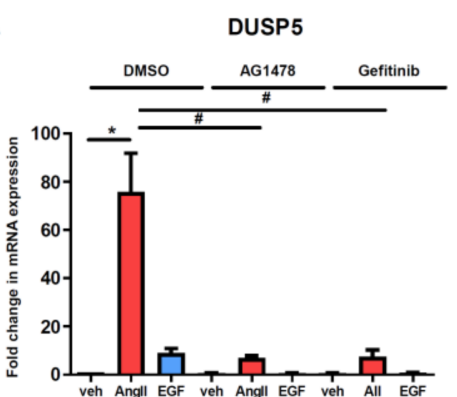

$\mathrm{D}$

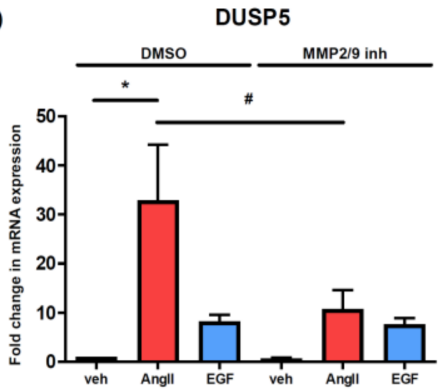

B

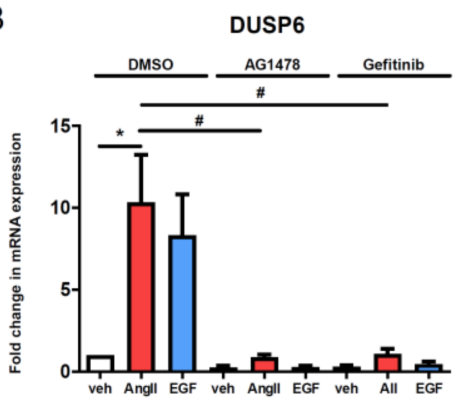

E
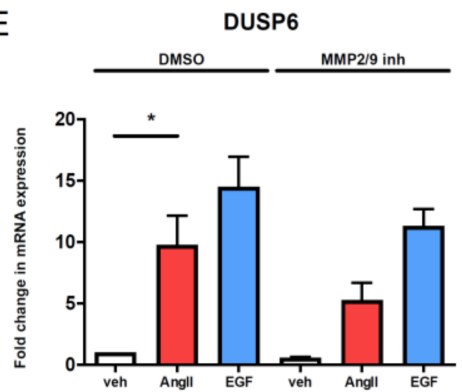

C

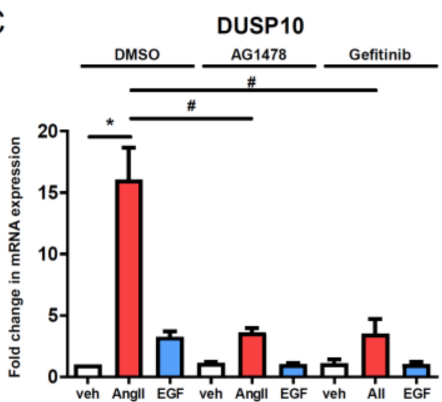

F

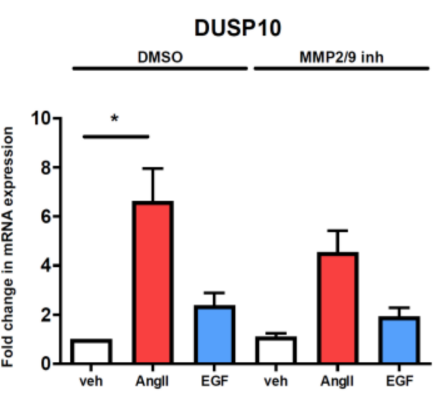

Figure 5. Effect of EGFR transactivation on the gene expressional changes of DUSP isoforms in VSMCs. Serum starved cells were incubated with either $1 \mu \mathrm{M}$ AG1478 (A-C) or $2.5 \mu \mathrm{M}$ gefitinib (A-C), or $1 \mu \mathrm{M}$ MMP-2/MMP-9 Inhibitor II (D-F) beside the control treated with DMSO for $30 \mathrm{~min}$, then the cells were exposed to either $100 \mathrm{nM}$ AngII (red columns) or $50 \mathrm{ng} / \mathrm{mL}$ EGF (blue columns) or vehicle (white columns) for $2 \mathrm{~h}$. mRNA levels of DUSP5 (A,D), DUSP6 (B,E) and DUSP10 $(\mathbf{C}, \mathbf{F})$ were measured by qPCR. Standardization was made against the GAPDH housekeeping gene. The mRNA levels were normalized to values of DMSO vehicle samples and expressed as fold change. The values are from three-six independent experiments. Mean values \pm S.E. are shown. Significance was determined with multiple linear regression. $p<0.05$ was considered as statistically significant. *: statistically significant from vehicle stimulation. \#: statistically significant from DMSO-pretreated agonist-induced response. The values are from three to six independent experiments $(n=3-6)$.

\subsection{Inhibition of Matrix Metalloproteinases Has a Moderate Effect on AngII-Induced DUSP Upregulation}

It is well documented that the matrix metalloproteinases are key mediators of AngIIinduced transactivation of EGFR in VSMCs and are important effectors of AngII-mediated vascular remodeling [1,6,7]. Among the MMPs, MMP-2 and MMP-9 appear to play the most important role in cardiovascular cells and, using a highly selective inhibitor, MMP-2/MMP9 Inhibitor II potently inhibited EGFR transactivation in VSMCs [7,33]. As expected, the MMP-2/MMP-9 Inhibitor II had no significant effect on direct EGFR activation-induced gene expression changes in DUSP genes (Figure 5D-F, blue columns). On the other hand, the MMP-2/MMP-9 Inhibitor II reduced the AngII-induced increase in DUSP5 but the inhibitory effect was not complete (Figure 5D, red column). Moreover, the MMP-2/MMP-9 
Inhibitor II had no significant effect on AngII-induced DUSP6 and DUSP10 upregulations (Figure 5E,F, red columns).

\subsection{The Role of Calcium Signaling and Calcium-Dependent Kinases in the Upregulation of DUSP Levels}

The stimulation of AT1 and EGF receptors induces a cytosolic calcium-level increase via the phospholipase $\beta$ and $\gamma$ activation mechanisms [1,34,35]. The agonist-induced calcium signal initiates several important regulatory mechanisms, such as the activation of protein kinase $\mathrm{C}$, proline-rich tyrosine kinase 2 (Pyk2) and calcium/calmodulin-dependent protein kinase in VSMCs [36-38]. We used $50 \mu \mathrm{M}$ BAPTA-AM (a permeant calcium chelator) pretreatment prior to agonist stimulation, to investigate the role of intracellular calcium in the regulation of DUSP mRNA levels. The results of the calcium chelation by BAPTA-AM demonstrate that the induced intracellular calcium elevation is essential for the observed upregulation of DUSP genes in response to both AngII and EGF stimulations in VSMCs (Supplementary Figure S2A-C). In order to further explore calcium signalrelated mechanisms, we applied a specific calcium/calmodulin-dependent protein kinase II (CaMKII) inhibitor, CK59. CaMKII plays an important role in AngII-induced vascular reactivity, hypertrophy in VSMCs, and vascular remodeling [39,40]. Supplementary Figure S2D-F illustrates that the inhibition of CaMKII with $50 \mu \mathrm{M}$ CK59 significantly attenuated the AngII-induced DUSP5 mRNA level increase but not the response caused by EGF. In the case of DUSP6 and DUSP10, the CK59 also significantly reduced the AngII-induced gene expression upregulations but the effect was much lower in the EGF-stimulated cells (Supplementary Figure S2D-F). To evaluate the role of the calcium-dependent protein kinase C (PKC), we employed the RO31-8425 compound, which is a highly selective inhibitor of PKC [41]. Pretreatment with the RO31-8425 PKC inhibitor ( $1 \mu \mathrm{M}$ for $10 \mathrm{~min})$ reduced the AngII- but not the EGFR-induced DUSP5 mRNA level increase (Supplementary Figure S3A-C). The inhibition of PKC resulted in a greatly reduced effect of AngII in DUSP6 and DUSP10 upregulation, whereas EGF-induced effects were moderately inhibited (Supplementary Figure S3A-C). Next, we investigated the involvement of Pyk2, a regulator of EGFR transactivation in VSMCs. We assessed the role of Pyk2 in the AngII induced upregulation of DUSPs by applying PF-562271, a potent ATP-competitive FAK and Pyk2 kinase inhibitor. Pretreatment of the cells with $1 \mu \mathrm{M}$ PF-562271 slightly but not significantly reduced the AngII-induced upregulation of DUSP5 and DUSP6 (Supplementary Figure S3D,E); the PF-562271 pretreatment did not influence the AngII-mediated gene expressional increase of DUSP10 either (Supplementary Figure S3F).

\subsection{Silencing of EGFR in VSMCs Using a Lentiviral shRNA System}

AngII stimulation can result in the much higher upregulation of DUSP5 and DUSP10 mRNA levels than direct EGFR stimulation by EGF (i.e., Figure 3A,B, red vs blue solid columns). The relative ineffectiveness of matrix metalloproteinase inhibition (Figure 5D-F) raised the possibility that AngII-induced DUSP upregulation is not entirely EGFR-transactivation-dependent. The effects of EGFR inhibitors (AG1478 and gefitinib in Figure 5A-C) on AngII-induced changes may reflect the off-target effects of these inhibitors [42-44]. In order to check the role of EGFR in AngII-induced DUSP upregulations, we decided to use the short hairpin RNA (shRNA)-based silencing of EGFR expression via RNA interference. As primary VSMC cultures are hard to transfect conventionally, we transduced VSMCs with pLKO.1 puro lentiviral constructs to produce siRNA specific to EGFR. First, we prepared two sets of lentiviruses containing different constructs. Following infection, we examined EGFR mRNA levels via real-time PCR (Figure 6A) and EGFR protein levels via Western blot analysis (Figure 6B). The results indicate that both constructs successfully reduced the expression and the protein levels of EGFR. Briefly, shEGFR\#2 was slightly more effective; therefore, we used this in our next experiments. 
A

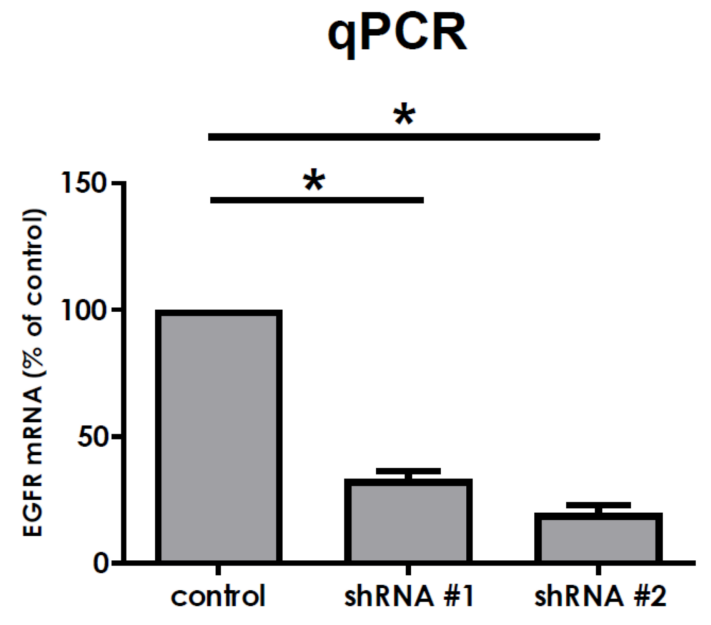

B

\section{Western blot}

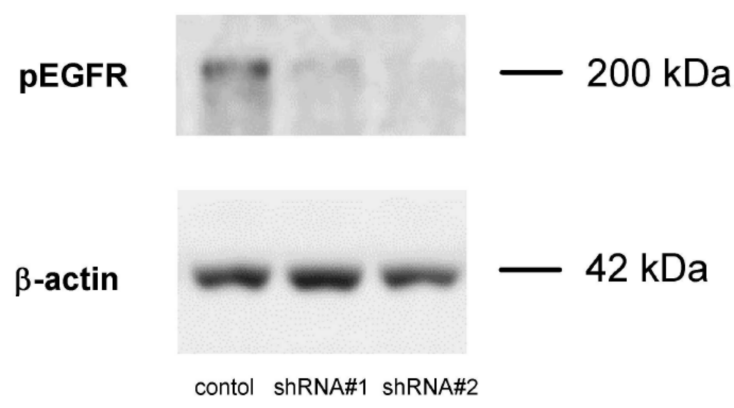

Figure 6. Silencing EGFR expression with shRNA constructs via lentiviral infection. VSMCs were infected with either shEGFR\#1 or shEGFR\#2 lentiviral constructs for $48 \mathrm{~h}$. Control-group cells were infected with a lentivirus coding-scrambled shRNA sequence. (A) EGFR gene expression levels were measured by a real-time PCR. Mean values \pm SE are shown. Significance was calculated with an ordinary one-way ANOVA test $\left.{ }^{*} p<0.05\right)$. (B) In the image, $5 \mathrm{~min}$ of $50 \mathrm{ng} / \mathrm{mL}$ EGF stimulationinduced phospho-EGFR levels were measured by Western blot analysis. Anti- $\beta$-actin staining was used as a loading control. The Western blots shown are representative of three independent experiments $(n=3)$.

The results shown in Figure 7 demonstrate that the shRNA silencing of EGFR has less effect on AngII-mediated gene expression changes than pharmacological inhibition. After waiting for $48 \mathrm{~h}$ after lentiviral infection with shRNA coding particles, VSMCs were stimulated with AngII or EGF, apart from a control group treated with the vehicle. The mRNA levels of DUSP isoforms were measured by real-time PCR. As expected, the silencing of EGFR completely wiped out the EGF stimulation-mediated DUSP level upregulations (Figure 7, blue columns). In contrast, the gene silencing of EGFR did not lead to such a dramatic blockade in the AngII-induced increase in DUSP mRNA levels, compared to the effect of AG1478 and gefitinib (Figure 7, red columns vs. Figure 5A-C, red columns). Moreover, the silencing of EGFR only caused a significant effect regarding the AngII-induced 
DUSP5 mRNA increase (Figure 7A, red columns) but in the case of DUSP6 and DUSP10, the EGFR silencing did not cause statistically significant effects (Figure 7B,C, red columns).

A

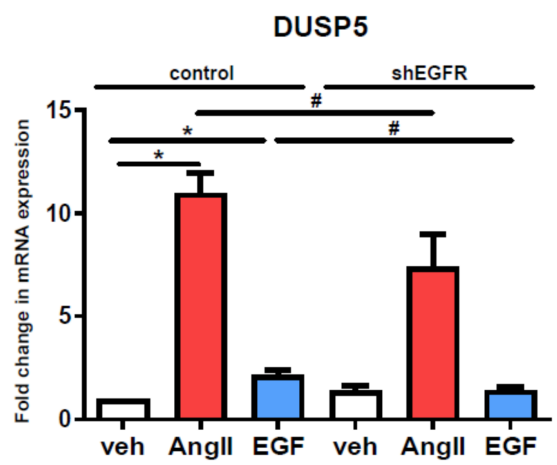

B

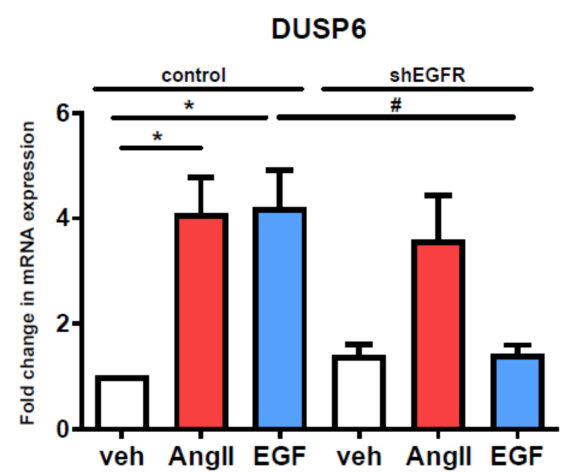

C

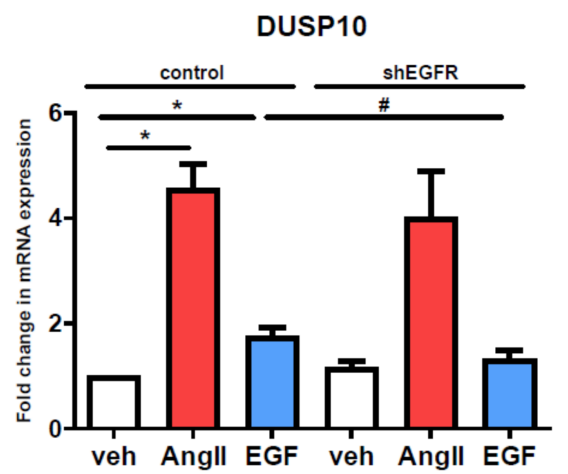

Figure 7. Effects of EGFR silencing on the gene expression responses to AngII and EGF stimuli in VSMCs. Primary vascular smooth muscle cells were infected with either scrambled (control) or shEGFR\#2 (shEGFR) shRNA coding lentiviral particles for $48 \mathrm{~h}$. Infected cells were stimulated for $2 \mathrm{~h}$ with either $100 \mathrm{nM}$ AngII (red columns), or $50 \mathrm{ng} / \mathrm{mL}$ EGF (blue columns) or vehicle (white columns) after $24 \mathrm{~h}$ of serum starvation. RNA was isolated from VSMCs, then converted to cDNA. cDNA levels of DUSP5 (A), DUSP6 (B) and DUSP10 (C) were measured by qRT-PCR. Standardization was made against the GAPDH housekeeping gene. The mRNA levels were normalized to values of control virusinfected and vehicle-stimulated samples and expressed as fold change. Mean values \pm S.E. are shown. Significance was determined with multiple linear regression. $p<0.05$ was considered as statistically significant. *: Statistically significant from vehicle stimulation. \#: Statistically significant from control virus-infected agonist-induced response. The values are from four independent experiments $(n=4)$.

\subsection{Role of Other Growth Factor Receptor Transactivation Mechanisms in the AngII-Induced Gene Expression Changes}

Although EGFR transactivation is considered to be the major growth factor receptor transactivation mechanism in VSMCs, the stimulation of $\mathrm{AT}_{1}-\mathrm{R}$ has also been confirmed to transactivate other growth factor receptors, including the platelet-derived growth factor receptor (PDGFR) and the insulin-like growth factor I receptor (IGF-IR) [45,46]. Inhibition of PDGFR with sunitinib or sorafenib pretreatments (Supplementary Figure S4A-C) and inhibition of IGF-IR with AG1024 or AG538 pretreatments (Supplementary Figure S4D-F) did not cause such robust effects as EGFR inhibition with AG1478 or gefitinib (Figure 5A-C) on AngII-induced DUSP expression levels. Only the sorafenib caused a significant reduction in AngII-induced gene expression changes, in the case of DUSP10, among these investigated drugs (Supplementary Figure S4C). These results indicate that PDGFR or IGF-IR transactivation is not a major signaling route to lead to AngII-induced upregulation of the investigated DUSP genes. 


\subsection{Effect of Simultaneous AngII and EGF Stimuli on DUSP Levels in VSMCs}

We used a different approach to confirm that AngII-induced gene expression changes are not exclusively EGFR transactivation-dependent. We stimulated the $\mathrm{AT}_{1}-\mathrm{R}$ and the EGFR together by applying simultaneous $100 \mathrm{nM}$ AngII and $50 \mathrm{ng} / \mathrm{mL}$ EGF stimuli of vascular smooth muscle cells. Surprisingly, the DUSP5 level was robustly upregulated. The DUSP5 expression level increased 2.24-fold in response to simultaneous AngII and EGF stimuli compared to single AngII stimulation, and 6.38-fold compared to only EGF stimulation (Figure 8A). Although the simultaneous AngII and EGF stimulations caused the highest increase in the DUSP6 level (Figure 8B), the combined effect of receptor agonists was not so striking as in the case of DUSP5. Similar to the evoked effect on DUSP5 level by simultaneous receptor activations, the DUSP10 mRNA level was also significantly upregulated by combined AngII and EGF stimulations; the DUSP10 expression level increased $\sim 1.69$-fold compared to only AngII stimulation, and $\sim 4$.17-fold compared to only EGF stimulation (Figure 8C). These results clearly demonstrate that there are synergistic pathways that may amplify each other, leading to robust gene expression changes in VSMCs, as in the case of DUSP5 and DUSP10 expression levels.

A

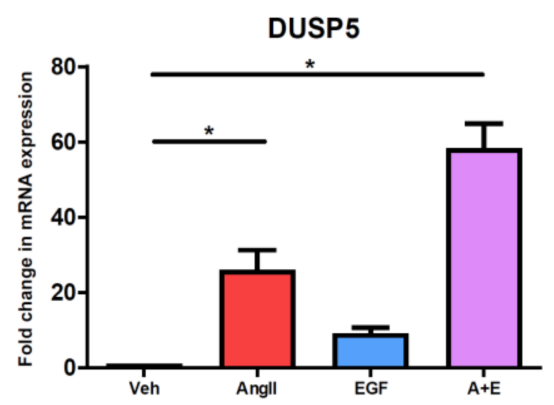

B

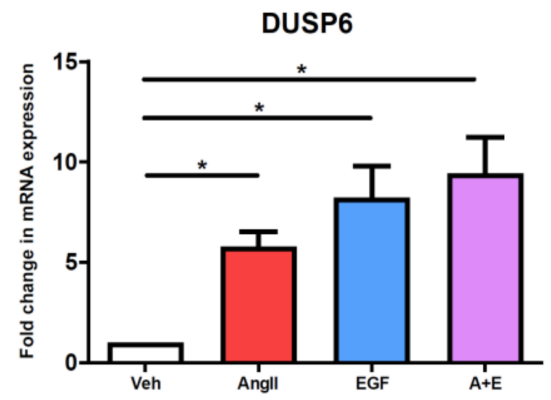

C

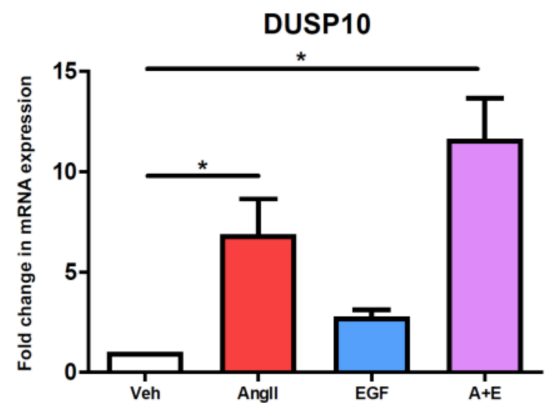

Figure 8. DUSP expression changes after simultaneous AngII and EGF stimuli in VSMCs. Serumstarved cells were exposed to either vehicle (white columns), or $100 \mathrm{nM}$ AngII (red columns), or $50 \mathrm{ng} / \mathrm{mL}$ EGF (blue columns), or simultaneously $100 \mathrm{nM}$ AngII and $50 \mathrm{ng} / \mathrm{mL}$ EGF (purple columns) for $2 \mathrm{~h}$. RNA was isolated from VSMCs, then converted to cDNA. cDNA levels of DUSP5 (A), DUSP6 (B) and DUSP10 (C) were measured by qRT-PCR. The mRNA levels were normalized to values of DMSO vehicle samples and expressed as a fold change. Mean values $\pm \mathrm{SE}$ are shown. Significance was determined with multiple linear regression $\left({ }^{*} p<0.05\right)$. The values are from seven independent experiments $(n=7)$.

\subsection{Effect of MAPK Signaling Inhibition on AngII-Induced DUSP Gene Upregulations}

Since the activity and expression of various DUSP isoforms are dependent on MAPKs [18], we aimed to evaluate the role of MAPKs in AngII-induced DUSP expression changes. We pretreated the cells with the PD98059 MEK inhibitor to assess the potential role of ERK1/2 
MAPKs in the AngII-evoked responses. The inhibition of the MEK significantly reduced the DUSP5 mRNA level increase upon AngII stimulation (Supplementary Figure S5A). Due to the dramatic effect of the PD98059 MEK inhibitor on basal DUSP6 and DUSP10 levels, the role of ERK1/2 MAPKs in AngII-induced DUSP6 and DUSP10 changes cannot be clearly established (Supplementary Figure S5B,C). On the contrary, the p38 MAPK inhibitor (SB202190) effectively reduced all the investigated AngII stimulation-caused DUSP mRNA level increases in VSMCs, whereas its inactive analog, SB202474, had no effect (Supplementary Figure S5D-F). These results indicate the important role of p38 MAPK signaling in the regulation of expression levels of DUSP5, DUSP6 and DUSP10 isoforms.

\section{Discussion}

Sustained AngII actions can lead to hypertension, vascular remodeling and atherosclerosis [1]; therefore, an evaluation of AngII-induced gene expression changes is important to clarify. New data can reveal previously unidentified mechanisms and new therapeutic agents to ameliorate AngII-triggered cardiovascular symptoms. Our results provide novel insights into the transcriptomic effects of AngII in primary rat VSMCs. The major findings of the present study are: (1) analyzing the transcriptomic effects and the gene expression changes of various DUSP isoforms in response to AngII stimulations of primary vascular smooth muscle cells and (2) demonstrating that $\mathrm{AT}_{1}-\mathrm{R}$ and EGFR can initiate synergistic signaling pathways to induce gene expression changes. These findings support the notion that $\mathrm{AT}_{1}-\mathrm{R}$ is capable of activating multiple signaling pathways that may be responsible for various cell responses.

Recent studies have already elucidated the importance of AngII-regulated gene expression changes in many cell types [8-13]. In this present study, we used rat primary VSMCs up to 3 passages in order to approximate them more closely to their physiological functions. We investigated the transcriptomic effect of AngII by stimulating serum-deprived early-passage VSMCs with the vehicle or $100 \mathrm{nM}$ AngII for two hours. We found many genes that were significantly upregulated or downregulated after AngII stimulation by using the Affymetrix GeneChip assay (Figure 1). In agreement with the previous gene-chip results, numerous earlier-described genes were identified in VSMCs $[9,10]$. The activation of $\mathrm{AT}_{1}-\mathrm{R}$ is followed by events leading to the downregulation of $\mathrm{AT}_{1}-\mathrm{R}$; in addition, the initiated signal transduction steps can be attenuated by various mechanisms, i.e., the phosphorylated proteins undergo dephosphorylation reactions. Our data demonstrate that Ang-II upregulates numerous genes, including dual-specificity phosphatases (DUSPs), which, in turn, can regulate the long-term MAPK signaling mechanisms of $\mathrm{AT}_{1}-\mathrm{R}$. Since the effect of AngII on DUSP gene expressions has not been reported, we wanted to investigate their roles in AngII signaling, and to identify which arm of the $\mathrm{AT}_{1}-\mathrm{R}$ signaling pathway is responsible for these effects. Among the identified genes, we have chosen to analyze one member from each subfamily of DUSP isoforms, namely, DUSP5, DUSP6 and DUSP10. Real-time PCR measurements demonstrated that the expression levels of the investigated DUSP genes increased $1 \mathrm{~h}$ after AngII stimulation, peaked at $2 \mathrm{~h}$ and persisted for up to $6 \mathrm{~h}$ (Figure 2). In the case of DUSP6, the kinetics of the expression were slightly different from those of DUSP5 and DUSP10, which indicates that the involved signaling pathways may vary in terms of the different AngII-evoked responses. We analyzed the possible signal transduction mechanisms that are responsible for the upregulation of the DUSP genes, in response to the AngII stimulation of VSMCs. The results revealed that the AngII effects are due to $A T_{1}-R$ activation caused by $G_{q} / 11$ protein coupling (Figure $4 A-C$ ). The activated $\mathrm{AT}_{1}$-Rs interact with $\beta$-arrestins that serve as organizers/scaffold platforms of signaling complexes, such as the activation of the MAP kinase cascade [47]. In order to evaluate the possible role of $\beta$-arrestin-mediated signaling in the regulation of expression changes, we applied TRV120023, a $\beta$-arrestin-biased $\mathrm{AT}_{1}-\mathrm{R}$ agonist, and the results indicated that $\beta$-arrestin has no significant role in the regulation of DUSP expression levels (Figure 4D-F). Since the $\mathrm{G}_{\mathrm{q}}$-dependent signaling of $\mathrm{AT}_{1}-\mathrm{R}$ activation leads to calcium signal and the activation of many calcium-dependent kinases in VSMCs, we investigated the effect of a 
calcium chelator, BAPTA-AM, and specific inhibitors of CaMKII, PKC, and Pyk2. The results demonstrated that the calcium signal and CaMKII play an essential role in all the investigated DUSP expression changes (Supplementary Figure S2D-F), whereas PKC and Pyk2 calcium-dependent kinases play no significant role in the AngII-induced DUSP5 and DUSP6 mRNA-level changes (Supplementary Figure S3). The DUSP10 level seems to be regulated only by PKC, not by Pyk2 activity (Supplementary Figure S3).

EGFR is a receptor tyrosine kinase, which is a key regulator in cardiovascular functions and plays many roles in VSMCs [48]. The stimulation of EGFR leads not just to the activation of Src family kinases and MAPKs promoting VSMC proliferation but also the calcium signal potentiating myogenic tone [49,50]. EGF stimulation was able to induce the DUSP6 mRNA level to a similar extent as the AngII but the EGF was less effective in the regulation of DUSP5 and DUSP10 levels (Figure 2). EGF-induced upregulation was wiped out by small-molecule EGFR kinase inhibitors (AG1478 and gefitinib), whereas the AngII-induced changes were significantly diminished by AG1478 or gefitinib pretreatment (Figure $4 \mathrm{~A}-\mathrm{C}$ ). The results regarding the inhibition of matrix metalloproteinases revealed that EGFR transactivation has no exclusive role in the regulation of AngII-induced DUSP mRNA levels, which finding was further confirmed in EGFR gene-silencing experiments (Figure 5D-F and Figure 7). Our experiments also proved that PDGFR or IGFIR transactivation has no significant role in the AngII-induced DUSP mRNA level changes, and only sorafenib caused a significant reduction in AngII-induced gene expression changes in the case of DUSP10 (Supplementary Figure S4). The AngII-induced EGFR transactivation depends on calcium signal, calcium-dependent Pyk2 and cytoplasmic Src-like tyrosine kinases [37,51,52]. Among the investigated DUSP isoforms, the DUSP5 upregulation is, at least partly, EGFR transactivation-dependent since either the inhibition of MMP enzymes by MMP-2/MMP-9 Inhibitor II or the silencing of EGFR by shRNA significantly reduced the effect of AngII stimulation. It is important to note that simultaneous AngII and EGF stimuli cause augmented DUSP levels compared to single AngII treatments (Figure 8), which indicates a synergistic role of EGFR- and $\mathrm{AT}_{1}$-R-induced signaling pathways and/or synergism of transcriptional factors in the regulation of DUSP levels. We may consider at least two mechanisms that lead to the upregulation of DUSP genes, an EGFR-dependent and an EGFR-independent mechanism. The EGFR transactivation-independent mechanisms are supported by the results that demonstrate less-efficient DUSP5 and DUSP10 upregulation by direct EGF stimulation compared to the AngII effect (Figure 3), and the partial effects of MMP2/9 inhibition and EGFR silencing (Figure 5A-C and Figure 7).

Mitogen-activated protein kinases (MAPKs) are important regulators of numerous cell functions including proliferation, apoptosis, and differentiation. Initially, the DUSP enzymes are considered as negative regulators of MAPK pathways [18], but it is possible that the various DUSPs and changes in their expression level can regulate/orchestrate the pattern of MAPK activation in response to repeated AngII stimuli. The gene expression induction of the various DUSPs in response to AngII stimulation is ultimately mediated by MAPK activity, primarily by ERK1/2 and p38 MAPKs (Supplementary Figure S5). It is possible that the AngII-induced DUSP5, DUSP6 and DUSP10 increase regulates the MAPK signaling in the long term in the VSMCs. The induced DUSPs may alter the MAPK signaling outcome (magnitude and duration) of subsequent stimulations. Both nuclearlocalized DUSP5 and cytoplasmic DUSP6 are known to be induced by ERK1/2 activity and they play an important role in the negative feedback loop to limit ERK1/2 activation. DUSP5 specifically interacts with and inactivates ERK1/2 but the DUSP5 itself is also regulated by ERK1/2 activity, i.e., the transcription of DUSP 5 mRNA is dependent on the phosphorylation of Elk-1 by ERK1/2 [53]. The overexpression of DUSP5 in cardiomyocytes results in ERK1/2 inactivation and the reduction of agonist-dependent hypertrophy [54], but it was recently demonstrated that although DUSP5 terminates nuclear ERK signaling and anchors ERK in the nucleus, DUSP5 increases the ERK activation in MEF cells [55]. DUSP6 is primarily located in the cytoplasm, binds to the activated ERK1/2, and causes the cytoplasmic retention of the inactivated ERK $1 / 2$ in the cytoplasm to play a role in the 
spatiotemporal regulation of MAPK activity [56]. It was demonstrated that DUSP6 gene expression and DUSP6 mRNA stability are controlled by the MEK-ERK1/2 pathways [57]. The DUSP6 KO mice showed increased basal ERK1/2 phosphorylation in multiple tissues and showed increased heart weight; however, this did not result in increased or prolonged ERK1/2 activation in response to stimulation, suggesting that DUSP6 is responsible for the fine-tuning of basal ERK1/2 activity [58]. Based on these findings, it is highly possible that DUSP5 and DUSP6 regulate the nucleo-cytoplasmic shuttling of ERK1/2, together sequestering the dephosphorylated ERK either in the nucleus or in the cytoplasm [18]. Our demonstrated results suggest that these DUSP isoforms can play an essential role in the regulation of MAPK signaling patterns in VSMCs. DUSP10, also called MKP-5, can be found in both the nucleus and cytoplasm, and is capable of regulating multiple MAPK pathways, including JNK, p38, and ERK1/2 MAPKs [59]. Among those pathways, the activated JNK and p38 MAPKs are more effectively dephosphorylated by DUSP10 than the ERK1/2 [60]. Interestingly, DUSP10 not only inactivates ERK MAPKs but also interacts with them. DUSP10 is capable of retaining ERK MAPKs in the cytoplasm and downregulating ERK-dependent transcription [61]. The multiple roles of DUSP10 in the regulation of MAPK signaling are also indicated in a study where the knockdown of DUSP10 inhibited acute EGF-stimulated ERK activation that could be reversed by the pharmacological inhibition of p38 MAPK, suggesting that DUSP10 may modulate crosstalk between the ERK1/2 and p38 MAPK pathways [62]. It is important to note that the expression of DUSP10 is elevated in various diseases, such as atherosclerosis [63], which may be the case in other pathophysiological conditions induced by the over-activation of $\mathrm{AT}_{1}-\mathrm{R}$. It is also possible that due to the not-exclusive substrate preference of certain DUSPs (i.e., DUSP10) and the crosstalk mechanisms in parallel MAPK pathways, the AngII stimulation-induced DUSPs can suppress or modify certain types of MAPKs, thus shaping the pattern/interplay of the MAPK network after repeated hormone stimuli. The confirmation of this possibility requires further study. In addition, the upregulated DUSP enzymes may regulate not just MAPKs but other proteins, either by dephosphorylating them and/or by binding to them. AngII-activated MAPK signaling also has implications in the phenotypic switching of VSMCs [64]. Since VSMC plasticity is an important factor in the physiological and pathological processes of the vasculature, we find that it is worthwhile to study the role of DUSPs in this context.

Our studies using the pharmacological inhibition of various signaling elements and the gene silencing of EGFR revealed that there is not an exclusive, or predominant, signal transduction pathway in primary rat VSMCs that leads to or may explain the investigated DUSP gene expression changes, and our experimental data shed light on the complex interplay/regulation among the signaling pathways. Our data showed that AngII-induced gene expression regulation is much more complex than we originally thought, due to the multiple signaling pathways that mediate them. The regulation of expression changes is very complex and is probably determined by the interplay of the involved signaling cascades. According to our data, different mechanisms can lead to the expression changes; classical $\mathrm{G}_{\mathrm{q} / 11}$ activation initiated the $\mathrm{Ca}^{2+}$-dependent mechanism, which induces EGFR transactivation-dependent and independent mechanisms. Further studies are needed to establish how the contributory signaling pathways could be successfully targeted in the treatment of diseases caused by $\mathrm{AT}_{1}-\mathrm{R}$ over-activation.

The pleiotropic effects of AngII on vascular smooth muscle cells contribute to the development of numerous cardiovascular diseases, such as hypertension, cardiac hypertrophy, and atherosclerosis. Our data provided new insights into the physiology of VSMCs in response to AngII stimulation, and a better understanding of the mechanisms of $\mathrm{AT}_{1}$ $\mathrm{R}$-mediated gene expression changes in primary VSMCs can lead to the development of novel types of drugs for the treatment of cardiovascular and other diseases. In addition, the $\mathrm{AT}_{1}-\mathrm{R}$ is a prototypical GPCR, with its pleiotropic action of mechanisms, so the described and revealed mechanisms can be considered valid in the case of other GPCRs in VSMCs. 
Supplementary Materials: The following are available online at https:/ / www.mdpi.com/article / 10.3390/cells10123538/s1, Figure S1: Verification of the basic properties of the isolated VSMCs; Figure S2. Role of calcium signal in gene expression changes of DUSP isoforms in VSMCs; Figure S3. Evaluation of the contribution of PKC signal transduction in the AngII- and EGF-induced gene expression changes of DUSP isoform in VSMCs; Figure S4. Effect of PDGFR and VEGFR and IGF-1R tyrosine kinase inhibitors on AngII and EGF mediated induction of DUSP expression in vascular smooth muscle cells; Figure S5. Importance of MAPK cascade activation in AngII mediated upregulation of DUSP isoforms in vascular smooth muscle cells.

Author Contributions: J.B.G., K.B.K., L.S., G.S., E.P., M.S. and A.B. performed the measurements. B.S., G.T., A.D.T., L.H. and A.B. conceptualized the work. All authors analyzed the results, wrote the manuscript, and approved the final version of the manuscript. All authors have read and agreed to the published version of the manuscript.

Funding: This work was supported by the Hungarian National Research, Development and Innovation Fund (NKFI K116954, NVKP_16-1-2016-0039 and VEKOP-2.3.2-16-2016-00002. B.S. was supported by the Premium Postdoctoral Fellowship Program of the Hungarian Academy of Sciences (460044).

Institutional Review Board Statement: The investigation conforms to the Guide for the Care and Use of Laboratory Animals (NIH, 8th edition, 2011) as well as to national legal and institutional guidelines for animal care. Their inclusion was approved by the Animal Care Committee of the Semmelweis University, Budapest and by Hungarian authorities (No. 001/2139-4/2012). All procedures followed legal and institutional guidelines of animal care.

Data Availability Statement: Data from Affymetrix GeneChip experiments will be available after publication.

Acknowledgments: The excellent technical assistance of Eszter Halász is greatly appreciated.

Conflicts of Interest: The authors declare no conflict of interest.

\section{References}

1. Forrester, S.J.; Booz, G.W.; Sigmund, C.D.; Coffman, T.M.; Kawai, T.; Rizzo, V.; Scalia, R.; Eguchi, S. Angiotensin II Signal Transduction: An Update on Mechanisms of Physiology and Pathophysiology. Physiol. Rev. 2018, 98, 1627-1738. [CrossRef] [PubMed]

2. Toth, A.D.; Turu, G.; Hunyady, L.; Balla, A. Novel Mechanisms of G-Protein-Coupled Receptors Functions: AT1 Angiotensin Receptor Acts as a Signaling Hub and Focal Point of Receptor Cross-Talk. Best Pr. Res. Clin. Endocrinol. Metab. 2018, 32, 69-82. [CrossRef] [PubMed]

3. Hunyady, L.; Catt, K.J. Pleiotropic AT1 Receptor Signaling Pathways Mediating Physiological and Pathogenic Actions of Angiotensin II. Mol. Endocrinol. 2006, 20, 953-970. [CrossRef]

4. Sauliere, A.; Bellot, M.; Paris, H.; Denis, C.; Finana, F.; Hansen, J.T.; Altie, M.F.; Seguelas, M.H.; Pathak, A.; Hansen, J.L.; et al. Deciphering Biased-Agonism Complexity Reveals a New Active AT1 Receptor Entity. Nat. Chem. Biol. 2012, 8, 622-630. [CrossRef] [PubMed]

5. Wei, H.; Ahn, S.; Shenoy, S.K.; Karnik, S.S.; Hunyady, L.; Luttrell, L.M.; Lefkowitz, R.J. Independent Beta-Arrestin 2 and G Protein-Mediated Pathways for Angiotensin II Activation of Extracellular Signal-Regulated Kinases 1 and 2. Proc. Natl. Acad. Sci. USA 2003, 100, 10782-10787. [CrossRef]

6. Mifune, M.; Ohtsu, H.; Suzuki, H.; Nakashima, H.; Brailoiu, E.; Dun, N.J.; Frank, G.D.; Inagami, T.; Higashiyama, S.; Thomas, W.G.; et al. G Protein Coupling and Second Messenger Generation Are Indispensable for Metalloprotease-Dependent, Heparin-Binding Epidermal Growth Factor Shedding through Angiotensin II Type-1 Receptor. J. Biol. Chem. 2005, 280, 26592-26599. [CrossRef]

7. Saito, S.; Frank, G.D.; Motley, E.D.; Dempsey, P.J.; Utsunomiya, H.; Inagami, T.; Eguchi, S. Metalloprotease Inhibitor Blocks Angiotensin II-Induced Migration through Inhibition of Epidermal Growth Factor Receptor Transactivation. BioChem. Biophys. Res. Commun. 2002, 294, 1023-1029. [CrossRef]

8. Szekeres, M.; Turu, G.; Orient, A.; Szalai, B.; Supeki, K.; Cserzo, M.; Varnai, P.; Hunyady, L. Mechanisms of Angiotensin II-Mediated Regulation of Aldosterone Synthase Expression in H295R Human Adrenocortical and Rat Adrenal Glomerulosa Cells. Mol. Cell. Endocrinol. 2009, 302, 244-253. [CrossRef] [PubMed]

9. Leung, A.; Trac, C.; Jin, W.; Lanting, L.; Akbany, A.; Saetrom, P.; Schones, D.E.; Natarajan, R. Novel Long Noncoding RNAs Are Regulated by Angiotensin II in Vascular Smooth Muscle Cells. Circ. Res. 2013, 113, 266-278. [CrossRef]

10. Jin, W.; Reddy, M.A.; Chen, Z.; Putta, S.; Lanting, L.; Kato, M.; Park, J.T.; Chandra, M.; Wang, C.; Tangirala, R.K.; et al. Small RNA Sequencing Reveals MicroRNAs That Modulate Angiotensin II Effects in Vascular Smooth Muscle Cells. J. Biol. Chem. 2012, 287, 15672-15683. [CrossRef] 
11. Christensen, G.L.; Knudsen, S.; Schneider, M.; Aplin, M.; Gammeltoft, S.; Sheikh, S.P.; Hansen, J.L. AT(1) Receptor Galphaq Protein-Independent Signalling Transcriptionally Activates Only a Few Genes Directly, but Robustly Potentiates Gene Regulation from the Beta2-Adrenergic Receptor. Mol. Cell. Endocrinol. 2011, 331, 49-56. [CrossRef]

12. Szekeres, M.; Nadasy, G.L.; Turu, G.; Supeki, K.; Szidonya, L.; Buday, L.; Chaplin, T.; Clark, A.J.; Hunyady, L. Angiotensin II-Induced Expression of Brain-Derived Neurotrophic Factor in Human and Rat Adrenocortical Cells. Endocrinology 2010, 151, 1695-1703. [CrossRef] [PubMed]

13. Nogueira, E.F.; Vargas, C.A.; Otis, M.; Gallo-Payet, N.; Bollag, W.B.; Rainey, W.E. Angiotensin-II Acute Regulation of Rapid Response Genes in Human, Bovine, and Rat Adrenocortical Cells. J. Mol. Endocrinol. 2007, 39, 365-374. [CrossRef] [PubMed]

14. Eguchi, S.; Hirata, Y.; Imai, T.; Kanno, K.; Marumo, F. Phenotypic Change of Endothelin Receptor Subtype in Cultured Rat Vascular Smooth Muscle Cells. Endocrinology 1994, 134, 222-228. [CrossRef] [PubMed]

15. Chamley-Campbell, J.H.; Campbell, G.R.; Ross, R. Phenotype-Dependent Response of Cultured Aortic Smooth Muscle to Serum Mitogens. J. Cell Biol. 1981, 89, 379-383. [CrossRef] [PubMed]

16. Mehta, P.K.; Griendling, K.K. Angiotensin II Cell Signaling: Physiological and Pathological Effects in the Cardiovascular System. Am. J. Physiol. Cell Physiol. 2007, 292, C82-C97. [CrossRef]

17. Patterson, K.I.; Brummer, T.; O'Brien, P.M.; Daly, R.J. Dual-Specificity Phosphatases: Critical Regulators with Diverse Cellular Targets. BioChem. J. 2009, 418, 475-489. [CrossRef]

18. Caunt, C.J.; Keyse, S.M. Dual-Specificity MAP Kinase Phosphatases (MKPs): Shaping the Outcome of MAP Kinase Signalling. FEBS J. 2013, 280, 489-504. [CrossRef]

19. Liu, R.; Molkentin, J.D. Regulation of Cardiac Hypertrophy and Remodeling through the Dual-Specificity MAPK Phosphatases (DUSPs). J. Mol. Cell. Cardiol. 2016, 101, 44-49. [CrossRef] [PubMed]

20. Liu, R.; van Berlo, J.H.; York, A.J.; Vagnozzi, R.J.; Maillet, M.; Molkentin, J.D. DUSP8 Regulates Cardiac Ventricular Remodeling by Altering ERK1/2 Signaling. Circ. Res. 2016, 119, 249-260. [CrossRef] [PubMed]

21. Elliott, K.J.; Eguchi, S. In Vitro Assays to Determine Smooth Muscle Cell Hypertrophy, Protein Content, and Fibrosis. Methods Mol. Biol. 2017, 1614, 147-153. [CrossRef]

22. Ritchie, M.E.; Phipson, B.; Wu, D.; Hu, Y.; Law, C.W.; Shi, W.; Smyth, G.K. Limma Powers Differential Expression Analyses for RNA-Sequencing and Microarray Studies. Nucleic Acids Res. 2015, 43, e47. [CrossRef]

23. Holland, C.H.; Szalai, B.; Saez-Rodriguez, J. Transfer of Regulatory Knowledge from Human to Mouse for Functional Genomics Analysis. Biochim. Biophys. Acta Gene Regul. Mech. 2020, 1863, 194431. [CrossRef]

24. Schubert, M.; Klinger, B.; Klünemann, M.; Sieber, A.; Uhlitz, F.; Sauer, S.; Garnett, M.J.; Blüthgen, N.; Saez-Rodriguez, J. Perturbation-Response Genes Reveal Signaling Footprints in Cancer Gene Expression. Nat. Commun. 2018, 9, 20. [CrossRef] [PubMed]

25. Stewart, S.A.; Dykxhoorn, D.M.; Palliser, D.; Mizuno, H.; Yu, E.Y.; An, D.S.; Sabatini, D.M.; Chen, I.S.; Hahn, W.C.; Sharp, P.A.; et al. Lentivirus-Delivered Stable Gene Silencing by RNAi in Primary Cells. RNA 2003, 9, 493-501. [CrossRef]

26. Szalai, B.; Saez-Rodriguez, J. Why Do Pathway Methods Work Better than They Should? FEBS Lett. 2020, 594, 4189-4200. [CrossRef] [PubMed]

27. Cosentino, F.; Savoia, C.; De Paolis, P.; Francia, P.; Russo, A.; Maffei, A.; Venturelli, V.; Schiavoni, M.; Lembo, G.; Volpe, M. Angiotensin II Type 2 Receptors Contribute to Vascular Responses in Spontaneously Hypertensive Rats Treated with Angiotensin II Type 1 Receptor Antagonists. Am. J. Hypertens. 2005, 18, 493-499. [CrossRef]

28. Ohtsu, H.; Higuchi, S.; Shirai, H.; Eguchi, K.; Suzuki, H.; Hinoki, A.; Brailoiu, E.; Eckhart, A.D.; Frank, G.D.; Eguchi, S. Central Role of Gq in the Hypertrophic Signal Transduction of Angiotensin II in Vascular Smooth Muscle Cells. Endocrinology 2008, 149, 3569-3575. [CrossRef]

29. Kawai, T.; Forrester, S.J.; O’Brien, S.; Baggett, A.; Rizzo, V.; Eguchi, S. AT1 Receptor Signaling Pathways in the Cardiovascular System. Pharm. Res. 2017, 125, 4-13. [CrossRef]

30. Violin, J.D.; DeWire, S.M.; Yamashita, D.; Rominger, D.H.; Nguyen, L.; Schiller, K.; Whalen, E.J.; Gowen, M.; Lark, M.W. Selectively Engaging Beta-Arrestins at the Angiotensin II Type 1 Receptor Reduces Blood Pressure and Increases Cardiac Performance. J. Pharm. Exp. Ther. 2010, 335, 572-579. [CrossRef]

31. Szakadati, G.; Toth, A.D.; Olah, I.; Erdelyi, L.S.; Balla, T.; Varnai, P.; Hunyady, L.; Balla, A. Investigation of the Fate of Type I Angiotensin Receptor after Biased Activation. Mol. Pharm. 2015, 87, 972-981. [CrossRef]

32. Devost, D.; Sleno, R.; Petrin, D.; Zhang, A.; Shinjo, Y.; Okde, R.; Aoki, J.; Inoue, A.; Hebert, T.E. Conformational Profiling of the AT1 Angiotensin II Receptor Reflects Biased Agonism, G Protein Coupling, and Cellular Context. J. Biol. Chem. 2017, 292, 5443-5456. [CrossRef] [PubMed]

33. Odenbach, J.; Wang, X.; Cooper, S.; Chow, F.L.; Oka, T.; Lopaschuk, G.; Kassiri, Z.; Fernandez-Patron, C. MMP-2 Mediates Angiotensin II-Induced Hypertension under the Transcriptional Control of MMP-7 and TACE. Hypertension 2011, 57, 123-130. [CrossRef] [PubMed]

34. Schreier, B.; Dohler, M.; Rabe, S.; Schneider, B.; Schwerdt, G.; Ruhs, S.; Sibilia, M.; Gotthardt, M.; Gekle, M.; Grossmann, C. Consequences of Epidermal Growth Factor Receptor (ErbB1) Loss for Vascular Smooth Muscle Cells from Mice with Targeted Deletion of ErbB1. Arter. Thromb. Vasc. Biol. 2011, 31, 1643-1652. [CrossRef] 
35. Zou, Z.G.; Rios, F.J.; Neves, K.B.; Alves-Lopes, R.; Ling, J.; Baillie, G.S.; Gao, X.; Fuller, W.; Camargo, L.L.; Gudermann, T.; et al. Epidermal Growth Factor Signaling through Transient Receptor Potential Melastatin 7 Cation Channel Regulates Vascular Smooth Muscle Cell Function. Clin. Sci. 2020, 134, 2019-2035. [CrossRef]

36. Shah, B.H.; Catt, K.J. Calcium-Independent Activation of Extracellularly Regulated Kinases 1 and 2 by Angiotensin II in Hepatic C9 Cells: Roles of Protein Kinase Cdelta, Src/Proline-Rich Tyrosine Kinase 2, and Epidermal Growth Receptor Trans-Activation. Mol. Pharm. 2002, 61, 343-351. [CrossRef]

37. Andreev, J.; Galisteo, M.L.; Kranenburg, O.; Logan, S.K.; Chiu, E.S.; Okigaki, M.; Cary, L.A.; Moolenaar, W.H.; Schlessinger, J. Src and Pyk2 Mediate G-Protein-Coupled Receptor Activation of Epidermal Growth Factor Receptor (EGFR) but Are Not Required for Coupling to the Mitogen-Activated Protein (MAP) Kinase Signaling Cascade. J. Biol. Chem. 2001, 276, 20130-20135. [CrossRef]

38. Eguchi, S.; Iwasaki, H.; Inagami, T.; Numaguchi, K.; Yamakawa, T.; Motley, E.D.; Owada, K.M.; Marumo, F.; Hirata, Y. Involvement of PYK2 in Angiotensin II Signaling of Vascular Smooth Muscle Cells. Hypertension 1999, 33, 201-206. [CrossRef]

39. Li, H.; Li, W.; Gupta, A.K.; Mohler, P.J.; Anderson, M.E.; Grumbach, I.M. Calmodulin Kinase II Is Required for Angiotensin II-Mediated Vascular Smooth Muscle Hypertrophy. Am. J. Physiol. Heart Circ. Physiol. 2010, 298, H688-H698. [CrossRef] [PubMed]

40. Prasad, A.M.; Nuno, D.W.; Koval, O.M.; Ketsawatsomkron, P.; Li, W.; Li, H.; Shen, F.Y.; Joiner, M.L.; Kutschke, W.; Weiss, R.M.; et al. Differential Control of Calcium Homeostasis and Vascular Reactivity by $\mathrm{Ca}^{2+} /$ Calmodulin-Dependent Kinase II. Hypertension 2013, 62, 434-441. [CrossRef]

41. Bit, R.A.; Davis, P.D.; Elliott, L.H.; Harris, W.; Hill, C.H.; Keech, E.; Kumar, H.; Lawton, G.; Maw, A.; Nixon, J.S.; et al. Inhibitors of Protein Kinase C. 3. Potent and Highly Selective Bisindolylmaleimides by Conformational Restriction. J. Med. Chem. 1993, 36, 21-29. [CrossRef]

42. Booij, T.H.; Klop, M.J.; Yan, K.; Szantai-Kis, C.; Szokol, B.; Orfi, L.; van de Water, B.; Keri, G.; Price, L.S. Development of a 3D Tissue Culture-Based High-Content Screening Platform That Uses Phenotypic Profiling to Discriminate Selective Inhibitors of Receptor Tyrosine Kinases. J. Biomol. Screen. 2016, 21, 912-922. [CrossRef] [PubMed]

43. Verma, N.; Rai, A.K.; Kaushik, V.; Brunnert, D.; Chahar, K.R.; Pandey, J.; Goyal, P. Identification of Gefitinib Off-Targets Using a Structure-Based Systems Biology Approach; Their Validation with Reverse Docking and Retrospective Data Mining. Sci. Rep. 2016, 6, 33949. [CrossRef] [PubMed]

44. Brehmer, D.; Greff, Z.; Godl, K.; Blencke, S.; Kurtenbach, A.; Weber, M.; Muller, S.; Klebl, B.; Cotten, M.; Keri, G.; et al. Cellular Targets of Gefitinib. Cancer Res. 2005, 65, 379-382. [PubMed]

45. Du, J.; Sperling, L.S.; Marrero, M.B.; Phillips, L.; Delafontaine, P. G-Protein and Tyrosine Kinase Receptor Cross-Talk in Rat Aortic Smooth Muscle Cells: Thrombin- and Angiotensin II-Induced Tyrosine Phosphorylation of Insulin Receptor Substrate-1 and Insulin-like Growth Factor 1 Receptor. BioChem. Biophys Res. Commun. 1996, 218, 934-939. [CrossRef]

46. Heeneman, S.; Haendeler, J.; Saito, Y.; Ishida, M.; Berk, B.C. Angiotensin II Induces Transactivation of Two Different Populations of the Platelet-Derived Growth Factor Beta Receptor. Key Role for the P66 Adaptor Protein Shc. J. Biol. Chem. 2000, 275, 15926-15932. [CrossRef] [PubMed]

47. Lefkowitz, R.J. Seven Transmembrane Receptors: Something Old, Something New. Acta Physiol. 2007, 190, 9-19. [CrossRef]

48. Makki, N.; Thiel, K.W.; Miller, F.J. The Epidermal Growth Factor Receptor and Its Ligands in Cardiovascular Disease. Int. J. Mol. Sci. 2013, 14, 20597-20613. [CrossRef] [PubMed]

49. Yin, X.; Polidano, E.; Faverdin, C.; Marche, P. Role of L-Type Calcium Channel Blocking in Epidermal Growth Factor ReceptorIndependent Activation of Extracellular Signal Regulated Kinase 1/2. J. Hypertens. 2005, 23, 337-350. [CrossRef]

50. Tomas, A.; Futter, C.E.; Eden, E.R. EGF Receptor Trafficking: Consequences for Signaling and Cancer. Trends Cell Biol. 2014, 24, 26-34. [CrossRef]

51. Bokemeyer, D.; Schmitz, U.; Kramer, H.J. Angiotensin II-Induced Growth of Vascular Smooth Muscle Cells Requires an SrcDependent Activation of the Epidermal Growth Factor Receptor. Kidney Int. 2000, 58, 549-558. [CrossRef] [PubMed]

52. Eguchi, S.; Numaguchi, K.; Iwasaki, H.; Matsumoto, T.; Yamakawa, T.; Utsunomiya, H.; Motley, E.D.; Kawakatsu, H.; Owada, K.M.; Hirata, Y.; et al. Calcium-Dependent Epidermal Growth Factor Receptor Transactivation Mediates the Angiotensin II-Induced Mitogen-Activated Protein Kinase Activation in Vascular Smooth Muscle Cells. J. Biol. Chem. 1998, 273, 8890-8896. [CrossRef]

53. Buffet, C.; Catelli, M.G.; Hecale-Perlemoine, K.; Bricaire, L.; Garcia, C.; Gallet-Dierick, A.; Rodriguez, S.; Cormier, F.; Groussin, L. Dual Specificity Phosphatase 5, a Specific Negative Regulator of ERK Signaling, Is Induced by Serum Response Factor and Elk-1 Transcription Factor. PLoS ONE 2015, 10, e0145484. [CrossRef] [PubMed]

54. Ferguson, B.S.; Harrison, B.C.; Jeong, M.Y.; Reid, B.G.; Wempe, M.F.; Wagner, F.F.; Holson, E.B.; McKinsey, T.A. Signal-Dependent Repression of DUSP5 by Class I HDACs Controls Nuclear ERK Activity and Cardiomyocyte Hypertrophy. Proc. Natl. Acad. Sci. USA 2013, 110, 9806-9811. [CrossRef] [PubMed]

55. Kidger, A.M.; Rushworth, L.K.; Stellzig, J.; Davidson, J.; Bryant, C.J.; Bayley, C.; Caddye, E.; Rogers, T.; Keyse, S.M.; Caunt, C.J. Dual-Specificity Phosphatase 5 Controls the Localized Inhibition, Propagation, and Transforming Potential of ERK Signaling. Proc. Natl. Acad. Sci. USA 2017, 114, E317-E326. [CrossRef] [PubMed]

56. Karlsson, M.; Mathers, J.; Dickinson, R.J.; Mandl, M.; Keyse, S.M. Both Nuclear-Cytoplasmic Shuttling of the Dual Specificity Phosphatase MKP-3 and Its Ability to Anchor MAP Kinase in the Cytoplasm Are Mediated by a Conserved Nuclear Export Signal. J. Biol. Chem. 2004, 279, 41882-41891. [CrossRef] [PubMed] 
57. Bermudez, O.; Jouandin, P.; Rottier, J.; Bourcier, C.; Pages, G.; Gimond, C. Post-Transcriptional Regulation of the DUSP6/MKP-3 Phosphatase by MEK/ERK Signaling and Hypoxia. J. Cell. Physiol. 2011, 226, 276-284. [CrossRef]

58. Maillet, M.; Purcell, N.H.; Sargent, M.A.; York, A.J.; Bueno, O.F.; Molkentin, J.D. DUSP6 (MKP3) Null Mice Show Enhanced ERK1/2 Phosphorylation at Baseline and Increased Myocyte Proliferation in the Heart Affecting Disease Susceptibility. J. Biol. Chem. 2008, 283, 31246-31255. [CrossRef]

59. Jimenez-Martinez, M.; Stamatakis, K.; Fresno, M. The Dual-Specificity Phosphatase 10 (DUSP10): Its Role in Cancer, Inflammation, and Immunity. Int. J. Mol. Sci. 2019, 20. [CrossRef]

60. Theodosiou, A.; Smith, A.; Gillieron, C.; Arkinstall, S.; Ashworth, A. MKP5, a New Member of the MAP Kinase Phosphatase Family, Which Selectively Dephosphorylates Stress-Activated Kinases. Oncogene 1999, 18, 6981-6988. [CrossRef] [PubMed]

61. Nomura, M.; Shiiba, K.; Katagiri, C.; Kasugai, I.; Masuda, K.; Sato, I.; Sato, M.; Kakugawa, Y.; Nomura, E.; Hayashi, K.; et al. Novel Function of MKP-5/DUSP10, a Phosphatase of Stress-Activated Kinases, on ERK-Dependent Gene Expression, and Upregulation of Its Gene Expression in Colon Carcinomas. Oncol. Rep. 2012, 28, 931-936. [CrossRef] [PubMed]

62. Finch, A.R.; Caunt, C.J.; Perrett, R.M.; Tsaneva-Atanasova, K.; McArdle, C.A. Dual Specificity Phosphatases 10 and 16 Are Positive Regulators of EGF-Stimulated ERK Activity: Indirect Regulation of ERK Signals by JNK/P38 Selective MAPK Phosphatases. Cell. Signal. 2012, 24, 1002-1011. [CrossRef] [PubMed]

63. Luo, L.J.; Liu, F.; Wang, X.Y.; Dai, T.Y.; Dai, Y.L.; Dong, C.; Ge, B.X. An Essential Function for MKP5 in the Formation of Oxidized Low Density Lipid-Induced Foam Cells. Cell. Signal. 2012, 24, 1889-1898. [CrossRef] [PubMed]

64. Montezano, A.C.; Nguyen Dinh Cat, A.; Rios, F.J.; Touyz, R.M. Angiotensin II and Vascular Injury. Curr. Hypertens. Rep. 2014, 16, 431. [CrossRef] [PubMed] 